Parte especial 



\section{El contrato de concesión de obras públicas en la nueva Ley de Contratos del Sector Público}

SUMARIO: I. IMPORTANCIA DE LA REGULACIÓN SOBRE EL CONTRATO DE CONCESIÓN DE OBRAS PÚBLICAS. II. LA EXISTENCIA DE DISTINTOS CAMINOS PARA ALCANZAR UN MISMO OBJETIVO. III. EL CONTRATO DE CONCESIÓN DE OBRAS PÚBLICAS Y LAS ENTIDADES DEL SECTOR PÚBLICO. IV. DEFINICIÓN Y CARACTERÍSTICAS DEL CONTRATO DE CONCESIÓN DE OBRAS PÚBLICAS. V. ACTUACIONES PREPARATORIAS Y PROCEDIMIENTO DE ADJUDICACIÓN. VI. CUMPLIMIENTO DEL CONTRATO. VII. FINANCIACIÓN. 1. ObTENCión de FINANCIACión ajENA. 2. Garantías a otorgar por el CONCESIONARIO. VIII. EXTINCIÓN DEL CONTRATO DE CONCESIÓN DE OBRAS PÚBLICAS. 1. EXTINCIÓN POR CUMPLIMIENTO. 2. EXTINCIÓN POR INVALIDEZ DEL CONTRATO. 3. RESOlUCiÓN DEL CONTRATO.

I. IMPORTANCIA DE LA REGULACIÓN SOBRE EL CONTRATO DE CONCESIÓN DE OBRAS PÚBLICAS

La regulación del contrato de concesión de obras públicas introducida por la Ley 13/2003 supuso una verdadera revolución en amplios sectores de la contratación administrativa, al ofrecer un marco legal suficiente para permitir, con seguridad y certidumbre, una adecuada participación de los sectores público y privado en el diseño, construcción y explotación de obras públicas. La Ley 30/2007, de Contratos del Sector Público (en adelante, "LCSP"), introduce algunas modificaciones puntuales en su regulación, si bien mantiene sustancialmente la misma configuración del contrato que tan buen resultado ha ofrecido en los escasos años que la nueva regulación viene aplicándose.

Es cierto que la participación entre los sectores público y privado no es algo ajeno a la contratación administrativa. Sin embargo, hasta la aprobación de la Ley 13/2003 (que introdujo un nuevo título V en el Texto Refundido de la Ley de Contratos de las Administraciones Públicas aprobado por 
Real Decreto Legislativo 2/2000, referido precisamente al contrato de concesión de obras públicas), la utilización de esta técnica de participación encontraba apoyo fundamentalmente en regulaciones sectoriales (por ejemplo, la relativa a autopistas de peaje), en figuras contractuales que no siempre se acomodaban a la complejidad de las obras públicas a construir y/o explotar (contratos de gestión de servicios público, con o sin ejecución de obras) o bien respondía en muchas ocasiones a diseños establecidos directamente por los propios Pliegos de cláusulas administrativas particulares. En estos últimos casos, el carácter meramente contractual (no normativo) de tales Pliegos, unido a la parquedad o insuficiencia de sus previsiones, ofrecían un marco inseguro, no sólo para el contratista y la propia Administración, sino también para las entidades que en principio podían estar dispuestas a financiar el proyecto.

No debe perderse de vista que uno de los elementos básicos para que esta figura contractual sea verdaderamente operativa y útil es que se introduzcan instrumentos de garantía que permitan al contratista obtener la financiación necesaria, para lo que, a su vez, es preciso ofrecer un marco estable, seguro y, por tanto, atractivo para las entidades financiadoras, especialmente si de lo que se trata es de operar mediante verdaderos proyectos de financiación ("project finance").

La nueva regulación introducida por la Ley 13/2003 y mantenida ahora sustancialmente por la LCSP, tiene las dos notas distintivas siguientes: por un lado, ofrece ese marco general imprescindible para que tanto los potenciales licitadores como las entidades financiadoras se sientan lo suficientemente cómodos como para participar en la ejecución de este tipo de contratos, normalmente de larga duración; por otro, la nueva regulación es lo suficientemente flexible como para permitir modalidades sustancialmente distintas.

Las Administraciones, dentro de dicho marco legal, podrán diseñar cada contrato de concesión de obras públicas en función de sus necesidades y objetivos, pues, en definitiva, los denominados "PPP” ("Public Private Partnership") no constituyen figuras monolíticas. No existe un modelo único, sino que en la práctica varían atendiendo a las circunstancias concurrentes y a las necesidades de interés público. Partiendo de una configuración estructural básica, se introducen modulaciones en función, entre otros aspectos, de las necesidades del tipo de obra a realizar y de las características de la explotación. Se trata, por tanto, de figuras abiertas y dinámicas que difícilmente podrían definirse dentro de unos parámetros perfectamente delimitados. De hecho, el legislador español ha sido sensible a esta realidad. 
La intensa experiencia, aunque en un corto periodo de tiempo, del contrato de concesión de obras públicas, pone claramente de manifiesto el acierto en la regulación de la nueva figura contractual. Y ello es especialmente destacable si se tiene en cuenta que las Administraciones normalmente son reacias a aplicar nuevas figuras contractuales carentes de recorrido práctico. El funcionario (y con ello normalmente las autoridades) suele ser poco proclive a cambiar sus costumbres. A pesar de ello, en pocos años la figura se ha mostrado útil para acometer, no sólo grandes obras públicas, sino también otras de menor tamaño e importancia. No se trata de una figura que sólo vaya a ser usada por la Administración del Estado o por las Comunidades Autónomas en relación con infraestructuras o servicios que requieran una importante inversión, sino que también puede ser idónea - y de hecho lo está siendo- para acometer y explotar obras de menor calado promovidas por otras Administraciones públicas (por ejemplo, aparcamientos subterráneos, colegios, residencias para la tercera edad etc.).

Un momento clave en esta evolución fue la convocatoria por la Comunidad de Madrid de ocho nuevos hospitales (Majadahonda, Parla, Coslada, San Sebastián de los Reyes, Vallecas, Arganda del Rey, Aranjuez y Valdemoro) bajo esta modalidad contractual. La acogida por los potenciales licitadores y por las entidades de financiación fue excelente, lo que se manifestó en una importante participación en los concursos y en una implicación clara de las entidades de crédito en el apoyo y financiación de obras que requerían importantes inversiones iniciales. Esta iniciativa y, por tanto, la existencia de esta experiencia contrastada (al menos en sus fases iniciales) ha prendido como un reguero de pólvora, sucediéndose posteriormente la convocatoria para la construcción y explotación de nuevos hospitales en otros lugares de España y de otras infraestructuras.

El éxito de la figura, a mi juicio, es clara. La experiencia adquirida en otros países, las limitaciones presupuestarias de las Administraciones Públicas para construir y explotar obras públicas, la necesidad de dar más y mejores servicios al ciudadano y, en fin, la existencia de un nuevo campo de negocio para los contratistas y para las entidades financiadoras, constituyen circunstancias suficientes como para poder augurar —y los hechos lo están demostrando ya - el intenso uso que de esta figura contractual van a seguir haciendo las Administraciones Públicas.

\section{LA EXISTENCIA DE DISTINTOS CAMINOS PARA ALCANZAR UN MISMO OBJETIVO}


La configuración del contrato de concesión de obras públicas como un contrato nominado o típico no excluye la posibilidad de que el objetivo que con el mismo se persigue pueda alcanzarse a través de otras figuras contractuales o en el marco de legislaciones sectoriales o generales distintas. De ello dependerá el régimen finalmente aplicable.

En efecto, no es extraño en la práctica encontrar situaciones en las que para la construcción y posterior explotación de una obra pública la Administración se plantea la vía a seguir, y ello es así porque jurídicamente se encuentra con diversas alternativas, de cuya elección dependerá la normativa aplicable.

Así, por ejemplo, la legislación de contratos, también la LCSP, admite la existencia de contratos de gestión de servicios públicos que incorporen la ejecución de obra. El artículo 255.1 de la LCSP señala que la ejecución del contrato de gestión de servicios públicos incluirá, en su caso, "la ejecución de las obras conforme al proyecto aprobado por el órgano de contratación”. Cuando el contrato comprenda la ejecución de obras y la explotación del servicio público, con algunas excepciones, el plazo de duración del contrato será de cincuenta ańos, muy superior al plazo establecido cuando el contrato comprenda sólo la explotación del servicio público.

Con independencia de que el principio de libertad de pactos previsto en el artículo 25 de la LCSP permite configurar los contratos en función de la necesidades de interés público, que no necesariamente deben acomodarse a alguno de los contratos nominados o típicos, lo cierto es que el contrato de gestión de servicios públicos (entendida esta última expresión en sentido amplio) que incorpora la ejecución de obra materialmente se asemeja en gran medida, al menos en cuanto a su objetivo, al contrato de concesión de obras públicas. Según elija la Administración una u otra modalidad contractual, el régimen público aplicable variará, en algunos aspectos de manera sustancial.

Mayor incidencia tiene aún si cabe el hecho de que en ocasiones las alternativas que se ofrecen a la Administración implican un cambio de legislación aplicable. Me estoy refiriendo a la posibilidad de trasladar la cuestión desde el marco de la legislación de contratos hacia la legislación de patrimonio, sectorial o general. En este último caso, la Administración perseguirá la construcción de una obra pública para su posterior explotación, si bien afrontará la cuestión a través del otorgamiento de una concesión demanial. En el título por el que se otorga la concesión de dominio público dispondrá los términos en los que el concesionario deberá construir la obra pública y su explotación posterior.

Nuevamente en este caso el objetivo es similar: construir una obra pública para su posterior explotación, si bien en este supuesto la característica estriba en que se pone el énfasis en el dominio público y en su uso privativo 
(concesión demanial), título que legitima la intervención en la construcción y posterior explotación del servicio que se presta a los usuarios y que determina que resulte de aplicación por dicho motivo la legislación de patrimonio general o sectorial.

Un ejemplo típico lo tenemos en el ámbito portuario, en el que tradicionalmente las autoridades portuarias, también bajo el marco de la Ley 48/2003, de 26 de noviembre, de régimen económico y de prestación de servicios de los puertos de interés general (que, sin embargo, recoge ya la figura del contrato de concesión de obras públicas), utilizan la concesión de dominio público portuario como instrumento a partir del cual se construirá la infraestructura portuaria de que se trate y se regulará en dicho título su posterior explotación económica, fijándose el plazo, tarifas, inversiones, etc.

Con ello quiero poner de manifiesto que antes y después de la regulación del contrato de concesión de obras públicas como un contrato nominado, las Administraciones han gozado de instrumentos para alcanzar fines similares a los perseguidos ahora con dicho contrato. Y aunque pudiera rechazarse la oportunidad de que la Administración goce de diversas alternativas, lo cierto es que en muchas ocasiones la situación es así, lo que obliga al operador jurídico necesariamente y con carácter previo a analizar cuál es la configuración que la Administración ha querido dar al supuesto, única forma de conocer con rigor el régimen jurídico que resultara de aplicación.

En definitiva, el contrato de concesión de obras públicas, con haberse demostrado eficaz y práctico, sin embargo no excluye la posibilidad de utilizar otras figuras jurídicas para alcanzar un mismo objetivo. Se ha de ser consciente de ello si realmente pretende comprenderse la forma en la que se ejecutan y explotan determinadas obras públicas.

\section{EL CONTRATO DE CONCESIÓN DE OBRAS PÚBLICAS Y LAS ENTIDADES DEL SECTOR PÚBLICO}

La LCSP constituye una Ley compleja en su lectura y comprensión. Es cierto que su estructura da una apariencia de correcta organización sistemática, siguiendo sucesivamente los pasos desde la preparación del contrato hasta su extinción (preparación, adjudicación, cumplimiento y efectos, y extinción). Sin embargo, se trata de un mero espejismo, ya que esta misma estructura lleva a una regulación diseminada a lo largo de toda la Ley de los aspectos específicos relativos a cada contrato, lo que sin duda dificulta enormemente la labor del operador jurídico.

A ello debe añadirse el hecho de que no siempre es fácil delimitar los aspectos incluidos en la LCSP que son aplicables a todas las entidades del 
sector público o sólo a parte de ellas, a pesar de que, como reconoce su exposición de motivos, se ha pretendido incrementar "la seguridad jurídica al eliminar remisiones imprecisas y clarificar las normas de aplicación”. Es decir, a mi juicio no se ha alcanzado el objetivo pretendido, fundamentalmente porque tras regularse en los artículos 173 a 176 de la LCSP las normas reguladoras de la adjudicación de contratos aplicables a las entidades del sector público que no son Administraciones Públicas (según la definición contenida en el artículo 3.2 de la LCSP), sin embargo existen numerosos preceptos diseminados a lo largo de la Ley que se refieren explícitamente a las entidades del sector público "in genere", y que, por tanto, gozan también de carácter imperativo para las entidades del sector público distintas de las Administraciones Públicas.

Sin querer dramatizar, sin embargo nos encontramos ante una situación normativa en cierta medida caótica que exigirá, no sólo un importante esfuerzo en las fases de interpretación y aplicación de la norma, sino también y especialmente en la fase de la búsqueda de la norma aplicable. Y es ciertamente poco alentador el esfuerzo que en ocasiones hay que realizar para intentar conocer la norma aplicable, labor necesariamente previa a la labor interpretativa.

Con un ejemplo se comprenderá mejor esta situación: la regulación específica del contrato de concesión de obras públicas que se contiene en la LCSP a veces se aplica a todas las entidades del sector público y a veces exclusivamente a las Administraciones Públicas (que son sólo un tipo de entidades del sector público).

En efecto, el artículo 7 de la LCSP define el contrato de concesión de obras públicas, precepto que se inserta en el Capítulo II "Contratos del sector público" del Título Preliminar, es decir, se trata de una definición que irradia sus efectos sobre todas las entidades del sector público (Administraciones Públicas, poderes adjudicadores distintos de las Administraciones Públicas y el resto de entidades del sector público). En cambio, los artículos 112 y siguientes de la LCSP regulan las actuaciones preparatorias del contrato de concesión de obras públicas, preceptos que se insertan el Título I "Preparación de contratos con las Administraciones Públicas" del Libro II, esto es, se trata de preceptos que no resultan de aplicación a las entidades del sector público distintas de las Administraciones Públicas (únicamente se dedica a la preparación de los contratos celebrados por poderes adjudicadores distintos de las Administraciones Públicas - lo que no incluye al resto de las entidades del sector público- el artículo 121). Por su parte, los artículos 223 a 250 de la LCSP regulan las especificidades en cuanto al cumplimiento y extinción de los contratos de concesión de obras públicas, preceptos que forman parte del Libro IV de la citada Ley referido concretamente a los 
"Efectos, cumplimiento y extinción de los contratos administrativos", siendo así que conforme señala el artículo 19 de la LCSP, sólo son contratos administrativos los celebrados por una Administración Pública (no las demás entidades del sector público), expresión ("Administraciones Públicas") entendida en los términos en los que, a efectos de la LCSP, se recogen en el artículo 3.2 de la misma, de lo que se desprende que tampoco resultarán de aplicación los artículos 223 a 250 a los contratos de concesión de obras públicas celebrados por entidades del sector público distintas de las Administraciones Públicas.

En otras palabras, nos encontramos con una definición del contrato de concesión de obras públicas (artículo 7 de la LCSP) que afecta a todas las entidades del sector público, y sin embargo la regulación específica del contrato resulta aplicable sólo a las Administraciones Públicas, y no al resto de las entidades del sector público. ¿Quiere decir ello que las entidades del sector público distintas de las Administraciones Públicas sólo están vinculadas por la definición del artículo 7 de la LCSP?; y de ser así, ¿qué virtualidad tendría esta vinculación si se tiene en cuenta el principio de libertad de pactos previsto en el artículo 25 de la LCSP y el hecho de que las entidades del sector público distintas de las Administraciones Públicas en realidad adjudican contratos de derecho privado?.

En definitiva, la LCSP se aplica con plenitud a las Administraciones Públicas, mientras que a los poderes adjudicadores distintos de las Administraciones Públicas y al resto de entidades del sector público se le aplicarán algunos de sus preceptos, que, por lo demás, se encuentran diseminados a lo largo de la Ley, lo que desde luego no coadyuva a obtener la certidumbre perseguida.

Ante esta situación, para la adecuada comprensión de la LCSP deben tenerse presente al menos los dos aspectos siguientes:

- La lectura de cualquier precepto, Sección, Capítulo, Título o Libro de la LCSP, debe hacerse necesariamente teniendo siempre presente la distinción entre los tres grupos de sujetos a los que, con un alcance diverso, les resulta de aplicación la LCSP, esto es, (i) las Administraciones Públicas definidas a los efectos de esta Ley en su artículo 3.2 (hay numerosas entidades públicas que nos son Administración Pública a los efectos de esta Ley ), (ii) poderes adjudicadores distintos de las Administraciones públicas (artículo 3.3) y (iii) el "resto" de entidades del sector público enumeradas en el artículo 3.1 y que no forman parte de ninguno de los dos grupos anteriores. Sobre esta base, deberá estarse atento a la utilización de expresiones como "contratos del sector público" (expresión omnicomprensiva que afecta a los tres grupos ci- 
tados), "contratos administrativos" (sólo los celebrados por las Administraciones Públicas), etc.

- Igualmente, habrá que tener en cuenta si se trata o no de contratos "sujetos a una regulación armonizada" (dimensión comunitaria) cuando quien contrate sea una Administración Pública o un poder adjudicador distinto de la Administración Pública. No así cuando se trate del "resto" de entidades del sector público, puesto que el artículo 13.1 de la LCSP define los contratos sujetos a una regulación armonizada por referencia a que la entidad contratante tenga el carácter de poder adjudicador, lo que denota que la distinción entre contratos de dimensión comunitaria y de índole nacional no opera respecto del "resto" (tercer grupo antes enunciado) de entidades del sector público.

Pues bien, la situación en lo que se refiere al contrato de concesión de obras públicas sería fundamentalmente la siguiente:

- Contratos adjudicados por las Administraciones Públicas en el sentido del artículo 3.2 de la LCSP: la preparación, adjudicación, efectos y extinción del contrato de concesión de obras públicas se regirá en bloque por la LCSP. Se tratará en todos los casos de "contratos administrativos", pues el artículo 19.1. ${ }^{\text {a) }}$ de la LCSP configura como tales los contratos de concesión de obras públicas celebrados por una Administración Pública.

- Contratos adjudicados por poderes adjudicadores distintos de las Administraciones Públicas (en el sentido del artículo 3.3 del TRLCAP): habrá que distinguir, a su vez, según pretenda adjudicarse un contrato de concesión de obras públicas "sujeto a una regulación armonizada" (dimensión comunitaria) o no.

En el primer caso (contrato de dimensión comunitaria), la adjudicación del contrato debe producirse siguiendo las reglas establecidas para la adjudicación de los contratos de las Administraciones Públicas en el Capítulo I del Título I del libro III (artículos 122 a 172 de la LCSP), con las matizaciones contenidas en el artículo 174 del mismo texto legal. Ahora bien, no resultará de aplicación -al menos directamente- la regulación prevista en la LCSP en relación con la preparación (con la matización prevista en el artículo 121 de la LCSP), efectos y extinción del contrato de concesión de obras públicas, ya que, como se ha visto antes, la regulación que se contiene sobre estas cuestiones en la LCSP se refiere específicamente a la preparación de contratos por "las Administraciones Públicas" (artículos 112 y siguientes) y a los efectos, cumplimiento y extinción de 
"los contratos administrativos" (artículos 223 y siguientes), expresiones ambas ("Administraciones Públicas" y "contratos administrativos") que dejan fuera a los poderes adjudicadores distintos de las Administraciones Públicas.

Es decir, un contrato de concesión de obras públicas de dimensión comunitaria (sujeto a una regulación armonizada) se adjudicará con algunas matizaciones - conforme a la LCSP, sin que le resulte de aplicación, sin embargo, el resto de la regulación específica prevista en la misma Ley para la preparación, efectos y extinción del contrato de concesión de obras públicas.

Si el poder adjudicador, en cambio, pretende adjudicar un contrato de concesión de obras públicas que carece de dimensión comunitaria, esto es, que no está sujeto a una regulación armonizada conforme señala el artículo 14 de la LCSP, en tal caso no resultará ya de aplicación la regulación específica prevista en la LCSP para la preparación, adjudicación, efectos y extinción de los contratos de concesión de obras públicas. Únicamente deberá adjudicarlos de conformidad con lo previsto en el artículo 175 de la LCSP, es decir, respetando los principios de publicidad, concurrencia, transparencia, confidencialidad, igualdad y no discriminación, utilizando para ello, en los términos señalados en el citado precepto legal, el "perfil de contratante" regulado en el artículo 42 de la LCSP.

- Contratos adjudicados por el "resto" de entidades del sector público distintas de las Administraciones Públicas y de los poderes adjudicadores: tampoco les resultará de aplicación la regulación que para los contratos de concesión de obras públicas se contienen en la LCSP en relación con su preparación, adjudicación, efectos y extinción. Únicamente habrán de adjudicar los contratos de acuerdo con lo previsto en el artículo 176 de la LCSP, utilizando para ello —en los términos señalados en dicho precepto legal- el "perfil de contratan$t e "$ de la entidad de que se trate.

Ahora bien, todo lo hasta ahora dicho no significa que no resulte de aplicación la LCSP en otros aspectos aun cuando quien vaya a adjudicar el contrato no sea una Administración Pública. Así, por ejemplo, aparte de la definición del contrato de concesión de obras públicas contenido en el artículo 7 de la LCSP y que pretende ser omnicomprensivo (aunque no se sabe con qué efecto práctico real, si es que lo tiene), resultará también de aplicación a todas las entidades del sector público la regulación contenida en el Libro I ("Configuración general de la contratación del sector público y elementos estructurales de los contratos") de la LCSP, ya que con las matizaciones 
que en dicho Libro se contienen, resultan de aplicación a la contratación de las entidades del sector público definidas en el artículo 3.1 (no sólo, por tanto, a las Administraciones Públicas). Así, por ejemplo, todo lo relativo a la capacidad, solvencia y ausencia de prohibición para contratar resulta aplicable a los tres grupos antes enunciados (Administraciones Públicas, poderes adjudicadores distintos de las Administraciones Públicas y resto de entidades del sector público), sin perjuicio de las matizaciones y especificidades previstas para cada uno de estos sujetos en tal regulación.

Otro tanto hay que decir, por ejemplo, del Titulo II ("Racionalización técnica de la contratación”) del Libro III, Título en el que se regulan los acuerdos marco, los sistemas dinámicos de contratación y las centrales de compras. El artículo 179 señala que "los sistemas para la racionalización de la contratación que establezcan las entidades del sector público que no tengan el carácter de Administraciones Públicas en sus normas e instrucciones propias, deberán ajustarse a las disposiciones de este Titulo para la adjudicación de contratos sujetos a regulación armonizada". Si se tiene en cuenta que con respecto al tercer grupo antes enunciado ("resto" de entidades del sector público distintas de las Administraciones Públicas y de los poderes adjudicadores) no opera la categoría de contratos sujetos a una regulación armonizada, el artículo 179 transcrito sólo puede estar refiriéndose a los poderes adjudicadores distintos de las Administraciones Públicas. O dicho de otra manera, el "resto" de entidades del sector público no están compelidos por la regulación que se contiene en el mencionado Título II.

A continuación me refiero al contrato de concesión de obras públicas como "contrato administrativo", esto es, el adjudicado por una Administración Pública en el sentido del artículo 3.2 de la LCSP. Y ello porque las entidades del sector público distintas de las Administraciones Públicas gozan, como se ha visto, de un margen mucho más amplio, bajo el principio de libertad de pactos, para configurar los contratos en los términos que estimen oportuno, siempre teniendo en cuenta, no obstante, los límites que dimanan del Código Civil y de los principios que informan la contratación de derecho privado, en particular, por lo que ahora interesa, el principio de que el cumplimiento del contrato no puede dejarse a la voluntad de una de las partes.

En efecto, prerrogativas o privilegios (poder de interpretación, modificación, suspensión o de resolución del contrato) que tienen sentido y son aceptadas en el contexto de contratos administrativos, son sin duda mucho más difícilmente encajables en el contexto de un contrato sometido al derecho privado, siendo así que, como se ha visto, las entidades del sector público distintas de las Administraciones Públicas suscriben contratos de derecho privado. 
Por ello, la tendencia que previsiblemente va a producirse de transformar actuales Pliegos de cláusulas administrativas particulares (en el marco de contratos administrativos) en Pliegos de contratos de derecho privado adjudicados por entidades del sector público distintas de las Administraciones Públicas, exigirá la necesaria adaptación de su contenido, pues sería difícilmente sostenible que a una de las partes en un contrato de derecho privado se le reconozca, sin fijarse adecuadamente sus contornos, la posibilidad de modificar unilateralmente su contenido, de interpretarlo o, en fin, de resolverlo cuando lo estime oportuno. Será preciso introducir las pertinentes modulaciones en la redacción, con el fin de adecuar los Pliegos a la naturaleza jurídica de la relación que se entabla (sometida al derecho privado).

\section{DEFINICIÓN Y CARACTERÍSTICAS DEL CONTRATO DE CONCESIÓN DE OBRAS PÚBLICAS}

El artículo 7 de la LCSP define el contrato de concesión de obras públicas, precepto que se inserta en el Capítulo relativo a los "Contratos del sector público". Como ya se ha expuesto, cabría preguntarse hasta que punto tiene sentido establecer una definición de esta figura contractual más allá de aquellos casos en los que el adjudicador sea una Administración Pública.

En efecto, tiene sentido que la LCSP defina el contrato de concesión de obras públicas en tanto en cuanto contrato susceptible de ser adjudicado por una Administración Pública y, por tanto, de asumir la condición de "contrato administrativo" de conformidad con lo establecido en el artículo 19.1. ${ }^{a}$ ) de la LCSP, al que le resultará de aplicación en bloque la LCSP. Ahora bien, pierde gran parte de su sentido que la definición del contrato de concesión de obras públicas opere en el marco de las adjudicaciones realizadas por entidades del sector público distintas de las Administraciones Públicas. Teniendo en cuenta que éstas adjudican contratos sometidos al derecho privado, carece de sentido las limitaciones que puedan dimanar de la propia definición contenida en el artículo 7 de la LCSP, ya que en realidad se gozará de un amplio margen - bajo el principio de libertad de pactos - para diseñar el contrato como mejor se estime conveniente; además, bastaría con no titularlo como "contrato de concesión de obras públicas" para hacer inoperativa, desde un punto de vista práctico, la definición del artículo 7 de la LCSP.

Pero refiriéndonos específicamente al contrato de concesión de obras públicas como "contrato administrativo" (es decir, cuando el adjudicador sea una Administración Pública), debe observarse que el artículo 7 de la LCSP introduce una importante novedad respecto a la regulación hasta 
ahora recogida en el Título IV del Libro II del Texto Refundido de la Ley de Contratos de las Administraciones Públicas aprobado por Real Decreto Legislativo 2/2000 (TRLCAP).

En efecto, el TRLCAP configuraba tres modalidades de contratos de concesión de obras públicas: (i) redacción de proyecto, ejecución de obra y explotación; (ii) ejecución de obra y explotación y (iii) sólo explotación de las obras. Como se observa, era imprescindible en todos los casos la presencia de la explotación de la obra pública, reconociéndose al concesionario el derecho a percibir una retribución consistente en la explotación de la propia obra, en dicho derecho acompañado de percibir un precio o en cualquier otra modalidad establecida en el propio Título V del Libro II del TRLCAP.

La novedad más sobresaliente que introduce ahora el artículo 7 de la LCSP consiste en que no se contempla ya la última modalidad, es decir, la explotación sólo de la obra pública. Las notas distintivas de la nueva configuración del contrato podrían resumirse en los siguientes términos:

- Puede incluir o no la presentación por el concesionario del correspondiente proyecto de las obras. Así se desprende, por ejemplo, del artículo 114.1 de la LCSP, cuando señala que el concesionario responderá de los daños derivados de los defectos del proyecto cuando, según los términos de la concesión, le corresponda su presentación o haya introducido mejoras en el propuesto por la Administración.

- Será preciso que el concesionario ejecute obras. Obsérvese que no digo que el concesionario deba ejecutar "las obras" que van a ser objeto de explotación posterior, sino que, en términos del artículo 7.1 de la LCSP, deberá realizar "algunas de las prestaciones a las que se refiere el artículo 6 , incluidas las de restauración y reparación de construcciones existentes". De ello se desprende las siguientes consecuencias:

- Como se ha destacado, no cabe el contrato de concesión de obras públicas en la modalidad de explotación exclusivamente.

- Ahora bien, el artículo 7 de la LCSP no exige la previa realización completa de las obras públicas que van a ser objeto posteriormente de explotación. Es decir, el contrato de concesión de obras públicas puede operar en relación con infraestructuras existentes sobre las que, no obstante, el concesionario realizará "algunas de las prestaciones" a que se refiere el artículo 6 de la LCSP (contrato de obras).

- La LCSP no exige un montante mínimo o porcentaje de obra a ejecutar por el concesionario, lo que permitirá, a tenor del artículo 7 de la LCSP, que pueda utilizarse esta figura contractual aun cuando las obras a ejecutar por el concesionario sean de entidad menor, por su 
escasa cuantía o importancia en proporción al contrato de concesión de obras públicas considerado en su globalidad. Bastará con realizar "algunas de las prestaciones" que constituyen el objeto típico del contrato de obras, esto es, los trabajos enumerados en el anexo I de la LCSP, "incluidas la restauración y reparación de las construcciones existentes".

En definitiva, aunque la LCSP formalmente se aparta de la regulación hasta ahora contenida en este aspecto en el TRLCAP, sin embargo desde un punto de vista práctico la inexistencia de porcentajes de obra pública a ejecutar o de parámetros similares, permitirán la utilización del contrato de concesión de obras públicas aunque la obra que se ejecute sea de escasa entidad. Por tanto, al menos desde un punto de vista práctico la situación sigue siendo muy similar, máxime si se tiene en cuenta que es difícilmente concebible otorgar la explotación de una obra pública existente sin incluir al menos exigencias relativas a la restauración y reparación de las mismas a cargo del concesionario, fundamentalmente porque se trata de contratos de larga duración.

Por lo demás, el artículo 7 de la LCSP permite que el contrato pueda comprender (no necesariamente deba comprender, como hasta ahora exigía el artículo 221 del TRLCAP) (i) la adecuación, reforma y modernización de la obra para adaptarla a las características técnicas y funcionales requeridas para la correcta prestación de los servicios o la realización de las actividades económicas a las que sirve de soporte material y (ii) las actuaciones de reposición y gran reparación que sean exigibles en relación con los elementos que ha de reunir cada una de las obras para mantenerse apta a fin de que los servicios y actividades a los que aquéllas sirven puedan ser desarrollados adecuadamente de acuerdo con las exigencias económicas y las demandas sociales.

- Explotación, conservación y mantenimiento. La LCSP se refiere explícitamente en el artículo 7.1 a la "conservación y mantenimiento" de los elementos constructivos como una nota característica del contrato de concesión de obras públicas. Y aunque no se refiere en similares términos a la "explotación" de la obra, ésta sigue configurándose, sin embargo, como el eje central que caracteriza este tipo de contrato. Así se desprende, por ejemplo, del hecho de que la contraprestación a favor del concesionario consista "únicamente en el derecho a explotar la obra o bien en dicho derecho acompañado del de percibir un precio". El primer derecho que reconoce al concesionario el artículo 228 de la LCSP es precisamente el "derecho a explotar la obra pública 
y percibir la retribución económica prevista en el contrato durante el tiempo de la concesión".

Conceptualmente no debe confundirse el mantenimiento o conservación de la obra con su explotación. El TRLCAP, al regular el contenido necesario del contrato de concesión de obra pública, diferenciaba en su artículo 221.1 entre:

“a) La explotación de las obras públicas conforme a su propia naturaleza y finalidad.

b) La conservación de las obras...".

La LCSP, aunque de una manera más confusa, sigue a mi juicio esta misma línea, al referirse a la "conservación y mantenimiento" por un lado y a la "explotación" por otro. "Conservar" y "explotar" constituyen actividades en sí mismas distintas, sin perjuicio de que la explotación lleve normalmente ínsita la necesaria conservación de la obra (no a la inversa). Si únicamente se encomendara al contratista la conservación de una obra, propiamente se estaría ante un contrato distinto del de concesión de obras públicas; por ejemplo, el artículo 106.1.c) de la LCSP, al establecer la clasificación de las obras (en el contexto del contrato de obras), incluye las "obras de conservación y mantenimiento". No se estaría ya propiamente ante un contrato de concesión de obras públicas, puesto que, como ya se ha destacado, la característica fundamental de este tipo de contratos consiste en que el contratista explote la obra, y a través de dicha vía obtenga la correspondiente retribución (acompańada de otras fuentes, en su caso).

Ahora bien, la realidad demuestra que no siempre es fácil establecer la línea divisoria entre "conservación y mantenimiento" y "explotación". Es más, la explotación, como se ha destacado, normalmente incluirá la conservación y mantenimiento; aquél es un concepto más amplio, que no sólo debe incluir la conservación y mantenimiento. La dificultad estriba en delimitar lo que se entiende por "explotación" de la obra pública.

En este sentido, es interesante traer a colación lo dispuesto en el artículo 126 de la Ley 48/2003, de régimen económico y de prestación de servicios de los puertos de interés general, referido al contrato de concesión de obras públicas en el ámbito portuario. Señala el citado precepto que "se entiende por explotación de una obra pública portuaria la puesta a disposición de la misma a favor de los prestadores de servicios o de los usuarios de aquélla para su ocupación, utilización o aprovechamiento, a cambio de la correspondiente retribución económica". 
Es decir, la explotación supone un plus respecto de la mera conservación o mantenimiento. No obstante, si conceptualmente esto puede ser claro, la realidad práctica demuestra que en ocasiones la actividad que se le encomienda al concesionario durante la fase de explotación se aparta poco de lo que es una mera conservación y mantenimiento de la obra pública.

- No cabe limitarse a la explotación de las "zonas complementarias de explotación comercial".

No sería viable limitarse a conservar la obra y explotar exclusivamente las "zonas complementarias de explotación comercial". En efecto, el artículo 231 de la LCSP permite que, atendiendo a su finalidad, “...las obras públicas puedan incluir, además de las superficies que sean precisas según su naturaleza, otras zonas o terrenos para la ejecución de actividades complementarias, comerciales industriales que sean necesarias o convenientes por la utilidad que prestan a los usuarios de las obras...". Y ello porque el citado precepto legal exige, por un lado, que tales zonas complementarias de explotación comercial "sean susceptibles de un aprovechamiento económico diferenciado, tales como establecimiento de hosteleria, estaciones de servicio, zonas de ocio, estacionamientos, locales comerciales y otros susceptibles de explotación", y, por otro, por el hecho de que se disponga que tales zonas o espacios quedarán sujetos al principio de unidad de gestión y control de la Administración Pública concedente y serán "explotados conjuntamente con la obra" por el concesionario directamente o a través de terceros en los términos establecidos en el oportuno Pliego de la concesión.

Ambas notas (y en particular la última de ellas) denotan que para considerar cumplido el requisito de la explotación de la obra (necesario para considerar existente un contrato de concesión de obras públicas) no bastará con encomendar al concesionario la explotación de las "zonas complementarias de explotación comercial'. Será preciso que, además, explote la obra pública en sentido estricto (las que el artículo 231 del TRLCAP denomina como "superficies que sean precisas según su naturaleza"), sin perjuicio de que dicha explotación no necesariamente deba ser exhaustiva en los términos y con el alcance que a continuación se expone.

Cuestión distinta es que sea admisible que la retribución del concesionario pueda provenir exclusivamente de los ingresos generados por la explotación de la zona comercial, aspecto al que me refiero más adelante.

- ¿Cabe la explotación no exhaustiva y agotadora de la obra?. Admitido lo anterior, el problema se centra en dilucidar si la LCSP exige que la explotación de la obra sea completa física y funcionalmente. Si se 
exigiera tal requisito, quedarían fuera del ámbito del contrato de concesión de obras públicas (al menos en los términos en los que actualmente se encuentre regulado) los contratos en los que el servicio que deba gestionar el concesionario (en su condición de explotador de la obra) no alcance la actividad completa que se desarrolla utilizando como soporte dicha obra.

Pues bien, a mi juicio efectivamente la LCSP configura la explotación de la obra como un elemento esencial del contrato de concesión de obras públicas. Pero lo que no exige la Ley, al menos explícitamente, es que la explotación de la obra deba ser necesariamente completa y exhaustiva, tanto en un sentido físico como funcional. Lo determinante es que la obra sea susceptible de explotación y que efectivamente sea explotada por el concesionario, vía a través de la cual obtendrá la retribución que le corresponda. Desde esta perspectiva, conviene destacar los dos aspectos siguientes:

a) Lo determinante es que la explotación de la obra permita finalmente remunerar los trabajos realizados (redacción de proyecto, construcción y explotación) por el concesionario. Si no fuera así, estaríamos ante otro tipo de contrato.

b) Incluso por razones de interés público es perfectamente posible concebir supuestos en los que a la Administración contratante le interese dejar fuera de la explotación una parte física de la obra o un aspecto funcional relacionado con la misma. En otro caso, se llegaría en ocasiones a situaciones cuando no absurdas sí al menos contrarias al interés público mismo. De alguna manera corrobora esta conclusión el hecho de que la regulación contenida en la LCSP se refiera en abstracto al régimen de utilización y explotación de la obra, dejando al Pliego de cláusulas administrativas particulares (en conexión con la proposición formulada por el licitador) la concreción de los términos en los que finalmente se acometerá la explotación de la obra.

Así, por ejemplo, el artículo 113.2.d) de la LCSP establece que el anteproyecto de construcción y explotación de la obra que eventualmente pueda redactarse en atención a la complejidad de dicha obra y al grado de definición de sus características, deberá contener, entre otra documentación, "un estudio relativo al régimen de utilización y explotación de la obra...”. En el artículo 115.1. a) se dispone que los Pliegos deberán contener, al menos, la definición del objeto de contrato, con referencia al anteproyecto o proyecto de que se trate y mención expresa de los documentos de éste que revistan 
carácter contractual. Asimismo, deberá contener los derechos y obligaciones específicos de las partes durante la fase de explotación, así como la referencia al contenido de las proposiciones, que, entre otros aspectos, deberá incluir el correspondiente plan económico-financiero de la concesión (que incorporará el sistema de tarifas, inversión, costes de explotación, etc.).

En definitiva, puede concluirse que la LCSP no ha establecido una figura herméticamente cerrada en lo que a la forma o alcance de la explotación de la obra se refiere, sino que, por el contrario, contiene abundantes remisiones (también en el aspecto de la explotación de la obra) a lo que pueda disponerse en los Pliegos.

De hecho, podrían distinguirse tres situaciones: (i) la explotación sólo de parte de la obra pública construida; (ii) la explotación de toda la obra pública pero sólo parcialmente desde el punto de vista funcional (es decir, no en todos los aspectos en los que la obra pública puede ser explotada); y (iii) explotación completa de la obra pública pero sólo durante un periodo de tiempo dentro del plazo total de duración del contrato.

La regulación vigente requiere que la explotación de la obra pública construida necesariamente deberá existir durante la vida completa del contrato, lo que significa que no cabe el supuesto (iii) antes señalado. Sin embargo, se insiste en que no existe una exigencia legal relativa a que la explotación deba cubrir la totalidad de la obra pública, razón por la que, a mi juicio, no existe inconveniente legal en admitir la explotación parcial de la obra pública en cualquiera de las dos modalidades (i) y (ii) señaladas.

Esta es precisamente la situación de los hospitales adjudicados por la Comunidad de Madrid y que han inaugurado la plena aplicación del contrato de concesión de obras públicas tras la regulación que introdujo en su día la Ley 13/2003. En relación con los citados hospitales (dejo a un lado el de Valdemoro, denominado de "bata blanca" al incluir también la prestación sanitaria propiamente dicha) sólo se encomienda al concesionario la explotación de determinados servicios (con alguna concreta matización, los servicios de limpieza, integral de seguridad, gestión de restauración, residuos urbanos y sanitarios, gestión de mantenimiento, conservación de viales y jardines, integral de lavandería, integral de esterilización, desinsectación y desratización, transporte interno-externo y gestión auxiliar, gestión de almacenes y distribución, y servicio de gestión de personal, administrativo o recepción/información y centralita telefónica). El resto de servicios (incluida la asistencia sanitaria propiamente dicha) la asume la Administración. Por tanto, no se trata de una explotación completa del hospital por parte del concesionario, posibilidad admisible, como he destacado, en el marco flexible que ofrecía el TRLCAP y que mantiene hoy la LCSP. 


\section{ACTUACIONES PREPARATORIAS Y PROCEDIMIENTO DE ADJUDICACIÓN}

En los artículos 112 al 115 de la LCSP se recogen las normas especiales para la preparación del contrato de concesión de obras públicas cuando el adjudicador sea una Administración Pública en el sentido del artículo 3.2. La regulación que se contiene en estos preceptos no varía sustancialmente de lo previsto en los artículos 227 y siguientes del TRLCAP.

La preparación del contrato se sigue estructurando sobre la base del estudio de viabilidad, que habrá de someterse a información pública y deberá ser informada por las Administraciones afectadas.

Es importante destacar que se mantiene la posibilidad de que el estudio de viabilidad sea de iniciativa privada. No es extraño a nuestro sistema jurídico la admisibilidad de que sean los particulares los que pongan de manifiesto ante la Administración la conveniencia y oportunidad de desarrollar determinadas actuaciones públicas.

La intervención del particular sólo afecta a la "iniciativa" propiamente dicha, dado que la tramitación y aprobación final lo será siempre de la Administración, que ni siquiera está obligada a asumir y tramitar el estudio de viabilidad presentado por el particular, sino únicamente a valorarlo y dar una contestación a quien lo presentó acerca de la decisión de tramitarlo o no. Las notas características de la iniciativa particular son las siguientes:

- Como se dice, no obliga a la Administración a aceptar y tramitar el estudio de viabilidad presentado por el particular, sino sólo a valorarlo, y consecuentemente a dar una contestación sobre su decisión de tramitarlo o no.

En el caso de que no haya contestación, operará el silencio administrativo negativo, lo que permitiría que quien tuvo la iniciativa pueda acudir ante la jurisdicción contencioso-administrativa. Ahora bien, difícilmente obtendría éxito en sus pretensiones si se tiene en cuenta que es a la Administración a la que le corresponde valorar el interés público y la oportunidad o conveniencia de construir una obra pública para su posterior explotación. Por ello, aunque se trata de una decisión en sí misma fiscalizable, difícilmente se obtendría una sentencia favorable en la que se condenara a la Administración a asumir y tramitar un estudio de viabilidad presentado por un particular, pues se entraría de lleno en lo que constituye la función de "administrar".

- La circunstancia de que la Administración asuma y tramite el estudio de viabilidad no genera derecho alguno a su aprobación final. La Administración, de igual manera que pudo no comenzar la tramitación 
del estudio presentado, puede en cualquier momento durante el procedimiento concluirlo anticipadamente, adoptando el correspondiente acuerdo en el que se plasme la inconveniencia de proseguir con la tramitación y, por tanto, de ejecutar y explotar las obras a que se refería el estudio de viabilidad.

- En el caso de que quien presentó el estudio de viabilidad resultara adjudicatario en la correspondiente licitación, no tendrá derecho a retribución alguna por los gastos ocasionados con motivo de la presentación de dicho estudio de viabilidad. En cambio, si no resultara adjudicatario, tendrá derecho al resarcimiento de los gastos efectuados para su elaboración incrementados en un 5 por 100 como compensación (el TRLCAP preveía un 10 por 100), "gastos que podrán imponerse al concesionario como condición contractual en el correspondiente pliego de cláusulas administrativas particulares".

Cuando el artículo 112.5 de la LCSP se refiere a que los gastos " $p o-$ drán imponerse al concesionario", no significa que el abono del resarcimiento de gastos y compensación a quien asumió la iniciativa del estudio de viabilidad esté en función de que se decida o no por la Administración imponérselos a quien resultó adjudicatario. La expresión "podrán imponerse al concesionario" debe entenderse en el sentido de que la Administración puede decidir repercutirlos a quien resulte adjudicatario, pero sin que de tal decisión nazca o no el derecho al resarcimiento a favor de quien tuvo la iniciativa. Si decide no repercutirlos, será la Administración la que directamente deberá abonarlos. Por lo demás, es la Administración la que fija el importe de los gastos a abonar en función de la documentación facilitada, siendo su decisión en este aspecto fiscalizable ante la jurisdicción contenciosoadministrativa.

Es posible sustituir el estudio de viabilidad por un "estudio de viabilidad económico-financiera" cuando por la naturaleza y finalidad de la obra o por la cuantía de la inversión requerida se considerara que éste es suficiente. Esta posibilidad de sustitución estaba prevista ya en el TRLCAP. Me interesa destacar que, a mi juicio, no parece que existan razones para negar la posibilidad de que la iniciativa privada en la presentación del estudio de viabilidad pueda también operar en relación con estudios de viabilidad económico-financiera. Si de lo que se trata es de fomentar en este y otros ámbitos la participación ciudadana - en este caso manifestada a través de la presentación de iniciativas - la circunstancia de que se trate de una obra peculiar o que requiera una inversión de cuantía limitada, no tiene necesariamente que 
impedir que pueda operar también la iniciativa privada, con las consecuencias ya señaladas.

Por lo demás, teniendo en cuenta que el contrato de concesión de obras públicas está llamado a cubrir situaciones que pueden variar sustancialmente, la LCSP, en línea de continuidad con el TRLCAP, permite distintas soluciones en cuanto a la existencia de anteproyectos de construcción y explotación y proyectos de obras. De esta manera, se admite la posibilidad de que, en función de la complejidad de la obra y del grado de definición de sus características, la Administración, aprobado el estudio de viabilidad, pueda acordar la redacción del correspondiente anteproyecto. A su vez, el proyecto de obra podrá ser redactado por la Administración concedente directamente, encargado a un tercero o bien impuesto al propio concesionario.

Dentro de este amplio margen de configuración del contrato de concesión de obras públicas, los Pliegos de cláusulas administrativas particulares juegan una función primordial. El artículo 115 de la LCSP señala el contenido mínimo de tales pliegos, y lo hace en términos suficientemente flexibles como para permitir que esta figura pueda ser eficaz en obras de distinta índole, con mecanismos de financiación y retribución que pueden ser sustancialmente diversos. Esta flexibilidad es quizá una de las razones fundamentales que se encuentran detrás del éxito de esta modalidad contractual.

\section{CUMPLIMIENTO DEL CONTRATO}

Los artículos 223 y siguientes de la LCSP regulan las peculiaridades de los efectos y extinción del contrato de concesión de obras públicas. Esta regulación no varía sustancialmente de la línea marcada por el TRLCAP. Me refiero a continuación brevemente a algunos aspectos de interés.

- Constitución de la sociedad concesionaria y transmisión de acciones.

Lo habitual en este tipo de contratos es que el Pliego exija — no sólo permita- la constitución de una sociedad ad hoc por los adjudicatarios, sociedad que asumirá la condición de concesionaria con sus correspondientes derechos y obligaciones. Ésta será, por tanto, la responsable frente a la Administración del cumplimiento y ejecución del contrato. De hecho es la que formalizará el contrato con la Administración.

Ello no obsta para que el Pliego pueda prever la responsabilidad directa de los adjudicatarios (accionistas de la sociedad concesionaria) en determinados aspectos, como por ejemplo mantener la ratio inversión/fondos propios. Es cierto que en algunas ocasiones los Pliegos han configurado un sis- 
tema en el se hacía responsables solidarios a los adjudicatarios y a la sociedad por ellos constituida (la sociedad concesionaria), lo que ha sido frontalmente contestado por el sector, puesto que hace perder en gran parte el atractivo de la figura, impide dotar de vida propia real y en cierta medida autónoma a la sociedad concesionaria constituida ad hoc y hace perder gran parte de su sentido a las exigencias que normalmente se prevén en los Pliegos relativas a los requisitos que habrá de reunir la citada sociedad concesionaria (capital social mínimo; ratio de la inversión cubierta con fondos propios, incluidos préstamos subordinados etc., aparte, obviamente, del desembolso de dividendos pasivos).

La sociedad concesionaria deberá estar participada por los accionistas en la misma proporción en la que participaron en la licitación al formular su oferta conjunta. No tendría sentido valorar, por ejemplo, la solvencia de los licitadores en trance de decidir la adjudicación del concurso y, sin embargo, que alguno o algunos de los licitadores (en oferta conjunta) valorados, no formaran parte finalmente de la sociedad concesionaria. A similar conclusión habría que llegar en relación con su participación concreta en el capital social de la sociedad concesionaria, puesto que perdería todo su sentido exigir en la fase de licitación que se comunique el porcentaje con el que participa cada licitador en el seno de la oferta conjunta si, a continuación, se hace caso omiso de tal circunstancia y se permite sin más constituir la sociedad concesionaria variando dichos porcentajes.

Cuestión distinta es la transmisión de acciones representativas del capital social de la sociedad concesionaria, una vez se encuentra constituida. Esta es una cuestión huérfana de regulación en la LCSP, como ya ocurría en el TRLCAP.

En efecto, la LCSP no contiene un precepto específico en el que se regule el régimen de transmisión de acciones de la sociedad concesionaria, lo que en muchas ocasiones provoca incertidumbre jurídica. En otras legislaciones sectoriales se regula específicamente cuándo hace falta solicitar autorización de la Administración para transmitir acciones; por ejemplo, en el artículo 117.4 en conexión con el artículo 77.1 ambos del Ley 48/2003, de régimen económico y de prestación de servicios de los puertos de interés general, se somete a previa autorización la transmisión de acciones de la sociedad concesionaria portuaria cuando, como consecuencia de dicha transmisión, el adquirente obtenga una posición que le permita influir de manera efectiva en la gestión o control de dicha sociedad. Se presume que concurre dicha situación de influencia efectiva cuando la participación directa o indirecta en el capital o en otros valores que confieran derechos políticos iguale o supere la proporción del 25 por ciento.

En realidad, la cuestión debe ser abordada en sus dos aspectos relevantes: 
- Si es preciso obtener la previa autorización de la Administración para transmitir acciones de la sociedad concesionaria (y, en su caso, el porcentaje cuya transmisión generaría la obligación de obtener dicha autorización previa) o si basta la mera comunicación a posteriori.

- Si podría considerarse (y en qué casos) que la transmisión de un porcentaje determinado de acciones de la sociedad concesionaria (o una transmisión que implique un cambio en el control de la sociedad concesionaria) equivale a la cesión del contrato, lo que exigiría el cumplimiento de los requisitos previstos en el artículo 209 de la LCSP (antiguo artículo 114 del TRLCAP).

Ante la referida ausencia de regulación de esta materia en el LCSP en los dos aspectos señalados, habrá de estarse a lo que prevea en cada caso el Pliego correspondiente. Si efectivamente el Pliego contiene previsiones sobre este particular (como en muchas ocasiones ocurre), habrá de estarse a lo en él previsto. Pero aun en este escenario, lo normal es que el Pliego, en lo que se refiere específicamente a la cesión, se limite a remitirse al precepto de la Ley de Contratos que regula la cesión de los contratos, lo que sin duda generará incertidumbre jurídica acerca del porcentaje de acciones que habrá de transmitirse para considerar que se produce efectivamente una cesión.

Además, dicha incertidumbre aumenta si se tiene en cuenta que el citado artículo 209 de la LCSP incluye como requisito para que sea viable la cesión que el cedente tenga ejecutado al menos un 20 por 100 del importe del contrato o, cuando se trate de la gestión de servicio público, que haya efectuado su explotación durante al menos una quinta parte del plazo de duración del contrato. Teniendo en cuenta que el contrato de concesión de obras públicas materialmente incluye la ejecución de obras y la explotación posterior, es cuando menos discutible si opera el requisito del 20 por 100 de ejecución de las obras o la quinta parte de prestación del servicio, o ambos requisitos según el estado de ejecución del contrato que exista cuando pretendan transmitirse las acciones (si es durante la fase de ejecución de las obras, operaría el citado requisito referido a las obras, y si se estuviera ya en fase de explotación sería aplicable el requisito de haber consumido al menos una quinta parte del plazo del contrato).

Aunque esta última podría ser la solución más acorde ante la falta de una regulación específica sobre el particular, sin embargo no dejaría de estar exenta de problemas que habría que resolver: por ejemplo, si a efectos de computar la quinta parte del plazo de explotación debería tomarse en consideración el plazo completo del contrato o sólo a partir del comienzo efectivo de explotación, aspecto relevante si se tiene en cuenta que normalmen- 
te el plazo otorgado al concesionario para la ejecución de las obras consume plazo de concesión. Además, no es extraño encontrar contratos con un objeto complejo, en los que simultáneamente comienzan las obras y la explotación propiamente dicha en algunos aspectos, lo que indudablemente complica las cosas.

En definitiva, esta falta de claridad sobre la cuestión aconseja que, previamente a la ejecución de una operación de este tipo respecto de la que puedan existir dudas, se obtenga de la Administración la previa conformidad. Debe tenerse presente el potencial riesgo que implicaría una cesión inconsentida, pues constituye una causa de resolución del contrato por causa imputable al concesionario.

\section{- Ejecución de las obras.}

Se permite que el concesionario pueda contratar con otras empresas la realización total o parcial de las obras objeto del contrato de concesión de obras públicas. Esta es la razón de que los Pliegos normalmente no exijan clasificación en obras al concesionario si no es quien va a ejecutar directamente las obras. El artículo 250 de la LCSP distingue las siguientes situaciones:

- Cuando el concesionario es "poder adjudicador" a efectos de la LCSP, deberá adjudicar al tercero el contrato de construcción de acuerdo con las normas que le resultan de aplicación, de conformidad con lo previsto en los artículos 174 y 175 de la LCSP. La circunstancia de que el citado poder adjudicador asuma la condición de contratista (concesionario de un contrato de concesión de obras públicas), no excluye que cuando contrata con tercero deba respetar las normas de contratación que le resultan de aplicación.

- Si el concesionario no tiene la condición de "poder adjudicador", podrían darse las siguientes situaciones:

* Si el constructor (quien va a ejecutar la obra pública) no es un "tercero" respecto del concesionario, podrá adjudicarle el contrato sin necesidad de seguir procedimiento de licitación alguno. No se consideran "terceros" a estos efectos aquellas empresas que se hayan agrupado para obtener la concesión, ni las empresas vinculadas a ellas. En este último aspecto, de acuerdo con lo dispuesto en el artículo 250 de la LCSP, se entiende por "empresas vinculadas" aquellas en las que el concesionario pueda ejercer, directa o indirectamente, una influencia dominante o aquellas que puedan ejercerla sobre él o, que del mismo modo que el concesionario, 
estén sometidas a la influencia dominante de otra empresa por razón de propiedad, participación financiera o normas que la regulen. Se presumirá que existe presencia dominante cuando una empresa, directa o indirectamente, con relación a otra: a) esté en posición de la mayoría del capital suscrito; b) disponga de la mayoría de los votos inherentes a las participaciones emitidas por la empresa, c) pueda designar más de la mitad de los miembros del órgano de administración, dirección o control de la empresa.

* Si el constructor fuera un "tercero" respecto del concesionario, habría que distinguir según el precio del contrato que se adjudica:

- Si el valor del contrato fuera igual o superior a 5.150 .000 e, el concesionario deberá someter los contratos que celebre con un "tercero" a las normas de publicidad establecidas en el artículo 126, salvo cuando concurran circunstancias que permitan su adjudicación mediante el procedimiento negociado sin publicidad. De acuerdo con el artículo 150.4 de la LCSP, el concesionario fijará el plazo de recepción de las solicitudes de participación, que no podrá ser inferior a treinta y siete días a partir de la fecha de envío del anuncio de licitación, y el plazo de recepción de las ofertas, que no podrá ser inferior a cuarenta días a partir de la fecha del envío del anuncio de licitación al Diario Oficial de la Unión Europea o de la invitación a presentar una oferta. Cuando los anuncios se preparen y envíen por medios electrónicos, informáticos o telemáticos se podrán reducir en siete días los plazos de recepción de las ofertas y el plazo de recepción de las solicitudes de participación. Será posible reducir en cinco días los plazos de recepción de las ofertas cuando se ofrezca acceso sin restricción, directo y completo, por medios electrónicos, informáticos o telemáticos, al pliego de condiciones y a cualquier documentación complementaria, especificando en el texto del anuncio la dirección de Internet en la que dicha documentación pueda consultarse. Esta reducción se podrá sumar a la anteriormente señalada.

- Si el valor del contrato fuera inferior a 5.150.000 €, el concesionario podrá adjudicar el contrato de obras al constructor sin necesidad de seguir las normas de publicidad citadas.

En el caso de empresas constructoras licitadoras en contratos de concesión de obras públicas, teniendo en cuenta que una parte importante del interés de la operación reside en la ejecución de las obras, es evidente que se 
buscará que éstas sean ejecutadas por las empresas agrupadas para obtener la concesión o por sociedades vinculadas a ellas en los términos señalados, con el fin de evitar que terceras empresas constructoras puedan finalmente ejecutarlas arrebatándoles con ello una parte importante del negocio.

Teniendo en cuenta la importancia que a estos efectos tiene la calificación de una empresa como "vinculada" o no a la licitadora, cabría plantearse qué ocurre cuando la empresa constructora a la que pretende adjudicarse la ejecución de la obra no es propiamente una "empresa vinculada" a alguna de las adjudicatarias que ofertaron conjuntamente (no aparece en ninguna de las listas de empresas vinculadas facilitadas por los licitadores en cumplimiento de lo previsto en el artículo 250.2 último párrafo de la LCSP) y, sin embargo, todas o algunas de las empresas adjudicatarias que ofertaron conjuntamente (que formularon una oferta conjunta) sí ejercen — conjuntamente - una influencia dominante.

Un ejemplo: resulta ganadora la oferta conjunta formulada por dos empresas, las cuales pretenden adjudicar la ejecución de las obras (directamente o la sociedad por ella constituida tras la adjudicación y que asume la condición de concesionaria) a una empresa constructora participada 50/50 por dichas adjudicatarias. Esta empresa constructora podrá no ser una "empresa vinculada" desde la perspectiva individual de cada una de las dos adjudicatarias, pero sin duda sí lo sería si se observa la situación desde la perspectiva conjunta de ambas. En estos casos, aunque pudiera no incluirse en el listado de empresas vinculadas, a mi juicio habría que sostener que no se trata propiamente de un "tercero" a los efectos de la adjudicación del contrato de obras por el concesionario. Es indudable que, aunque fuera conjuntamente, quienes resultaron adjudicatarios ejercerían sobre ella una influencia dominante en el sentido del artículo 250 de la LCSP, circunstancia que habría que tomar en consideración en trance de calificar la situación.

Por lo demás, el contrato de construcción que el concesionario suscriba con la empresa constructora normalmente responderá a la configuración de los contratos "llave en mano", en el que, además, el concesionario repercutirá sobre el constructor cualquier vicisitud adversa que aquél sufra frente a la Administración (en el marco del contrato de concesión) como consecuencia de la ejecución del contrato de construcción por el constructor. Este último contrato es de naturaleza privada y del mismo nada tiene que decir la Administración, puesto que el constructor no entabla relación jurídica alguna con la Administración (asume a estos efectos la condición de subcontratista). Sin embargo, se trata de un contrato de especial relevancia para las entidades financiadoras, en cuanto que les interesa y controlan que efectivamente se produzca la aludida repercusión sobre el constructor, con el fin de asegurar o 
reducir el riesgo de sobrecostes que deban ser asumidos por el concesionario, con su correspondiente impacto sobre el "caso base financiero".

- Transferencia al concesionario del riesgo de construcción y explotación. Matizaciones.

En el contrato de concesión de obras públicas también rige el principio de riesgo y ventura, lo que se traduce en que el concesionario asume los riesgos derivados de la construcción de la obra y de su posterior explotación. El artículo 225 de la LCSP se refiere a la aplicación del citado principio durante la ejecución de las obras, mientras que el artículo 229.b) del mismo texto legal alude a la obligación del concesionario de "explotar la obra pública, asumiendo el riesgo económico de su gestión con la continuidad y en los términos establecidos en el contrato u ordenados posteriormente por el órgano de contratación".

Ahora bien, el principio de riesgo y ventura se ve matizado como consecuencia de la aplicación de técnicas dirigidas a restablecer el equilibrio económico del contrato, tales como la doctrina del "riesgo imprevisible", "factum principis" o, en fin, el derecho que ostenta el concesionario a ser compensado cuando se producen casos de fuerza mayor.

En efecto, el principio de riesgo y ventura no tiene carácter absoluto, pues existen situaciones especiales o extraordinarias que justifican el reconocimiento del derecho del contratista el reequilibrio económico financiero del contrato.

$Y$ es que en realidad el citado principio rige en situaciones de normalidad, esto es, cuando no sobrevienen circunstancias imprevistas o extraordinarias que alteran sustancialmente los términos en los que se contrató. En estos casos, cuando además se genera un sensible desequilibrio entre las prestaciones a las que se obligan las partes contratantes, el concesionario puede llegar a ostentar un derecho al reequilibrio a través de distintos cauces, con apoyo en el hecho de que no se estaría ya dentro de lo que cabría concebir como "alea" normal del contrato. Principios como el de la interdicción del enriquecimiento injusto, proporcionalidad o la cláusula "rebus sic stantibus", justifican la aplicación de técnicas que permitan el reestablecimiento del reequilibrio y, en definitiva, que el contratista siga asumiendo el "alea" normal del contrato.

Como ha destacado el Consejo de Estado en el dictamen 3205/2003, de 21 de noviembre (reiterando la doctrina sentada en numerosos dictámenes anteriores), la obligatoriedad de las prestaciones debidas por las partes cede en el caso de que su cumplimiento resulte excesivamente oneroso, hasta el punto de alterar los presupuestos del negocio (la propia base del negocio) o sus condiciones (cláusula "rebus sic stantibus"). La gravosa onerosidad puede 
tener un origen vario, bien en decisiones de la propia Administración "factum principis", bien en circunstancias ajenas a ésta, bien en la fuerza mayor. Se trata de supuestos que alteran gravemente la economía del contrato y que generan un riesgo que "no es normal sino patológico y desmesurado, y de tal suerte que lo desbarata totalmente".

Obviamente, estas técnicas de reequilibrio constituyen excepciones al principio de riesgo y ventura, y como tales deben ser concebidas y aplicadas.

No voy a adentrarme ahora en el análisis de cada una de estas figuras. Pero sí me interesa destacar que tanto el TRLCAP como ahora la LCSP contienen una previsión que en cierta medida constituye otra importante matización (configurada no ya como una situación extraordinaria o imprevisible) al principio de riesgo y ventura: se permite que los Pliegos puedan asegurar al concesionario un canon de demanda mínimo. El artículo 115.1.C.4. ${ }^{\circ}$ de la LCSP señala que las proposiciones deberán contener el Plan económico-financiero de la concesión que incluirá “...en otras variables de la concesión previstas en el pliego, en su caso, de los rendimientos de la demanda de utilización de la obra y, cuando exista, de los beneficios derivados de la explotación de la zona comercial, cuando no alcancen o cuando superen los niveles minimo y máximo, respectivamente, que se consideren en la oferta" (en el mismo sentido se expresa el artículo 238.3 de la LCSP).

Es decir, puede preverse en el Pliego (y no es extraño encontrar ejemplos de ello) que si la demanda disminuye más allá de una determinado límite, la Administración garantizará dicha demanda mínima, de igual forma que si la demanda sobrepasa un límite máximo, se procederá al reequilibrio a favor de la Administración.

Esta configuración tiene, como se ve, cabida en la normativa vigente, posibilidad que de ser utilizada ofrecerá mayor confort a las entidades financiadoras. Sin embargo, puede llegar a plantear dudas desde la perspectiva de las normas de contabilidad Eurostat, fundamentalmente porque podría cuestionarse que se esté trasladando el riesgo al concesionario, y caso de considerarse que no se produce dicho traslado del riesgo desde la Administración hacia el concesionario, podría computar como deuda de la Administración concedente. Esta cuestión requiere alguna matización.

En efecto, en el año 2004 la Oficina de Estadística de las Comunidades Europeas (Eurostat) tomó una Decisión sobre la contabilización en la contabilidad nacional de los contratos suscritos por agencias gubernamentales dentro del marco de actuaciones con empresas no gubernamentales. En ella se define el impacto sobre el déficit/superávit y deuda nacional.

En este sentido, Eurostat considera que para que los activos resultantes de una acción pública-privada no deban ser registrados contablemente en el 
balance de los gobiernos (en sentido amplio), es preciso que se cumplan las dos condiciones siguientes:

- que el socio privado asuma el riesgo de construcción, y

- que asuma igualmente al menos uno de los dos riesgos de disponibilidad o de demanda.

Desde la perspectiva de la asunción del riesgo de construcción, la Decisión Eurostat aclara que asumir el riesgo para una de las partes significa que ésta "asume la mayor parte del riesgo". El riesgo de construcción se refiere particularmente a acontecimientos tales como el retraso en la entrega, el incumplimiento de estándares específicos, costes adicionales, deficiencias técnicas y efectos negativos externos. Se añade que la obligación de una Administración de comenzar a realizar pagos periódicos a un socio privado sin tener en cuenta el estado efectivo de los activos, constituiría una evidencia de que la Administración asume la mayoría de los riesgos de construcción.

En todo caso, para evitar la contabilización de este tipo de operaciones por la Administración contratante es preciso que concurra, a su vez, el requisito de que el socio privado asuma al menos uno de los dos riesgos de disponibilidad o de demanda.

En cuanto al riesgo de disponibilidad, se entiende que la Administración no asume dicho riesgo si tiene derecho a reducir de manera significativa sus pagos periódicos como consecuencia de la reducción en la entrega por el socio privado del volumen contractualmente acordado o cuando no se cumplen los estándares de calidad establecidos.

Y respecto al riesgo de demanda, se consideraría que lo asume la Administración cuando se obliga a mantener un volumen determinado de pagos al socio con independencia del nivel de la demanda efectiva de usuarios, es decir, cuando se convierten en irrelevantes las fluctuaciones de la demanda para los rendimientos económicos del socio privado (salvo que la valoración de la demanda fuera el resultado de acciones de gobierno).

De ello se desprende lo siguiente:

- Para que la Administración no registre como propia la deuda de la operación, será preciso - como requisito ineludible (aunque no suficiente) — que el riesgo de construcción sea asumido por el socio privado.

- A estos efectos, es preciso distinguir entre la "asunción del riesgo" y la "asunción total del riesgo". La Decisión Eurostat aclara que basta con asumir "la mayor parte" del riesgo para entender, a efectos de contabilización, que se asume el riesgo de construcción. Por tanto, la circunstancia de que la Administración asuma parte del riesgo de construc- 
ción, no comporta la obligación de consolidar desde un punto de vista contable, siempre que la otra parte en el contrato (el socio privado) asuma "la mayor parte" del riesgo.

- Para delimitar el grado de asunción del riesgo de construcción por la Administración y por el socio privado, será imprescindible atender al contenido de las cláusulas del contrato y de la normativa al mismo aplicable.

En estas circunstancias, asegurar una demanda mínima al concesionario podría generar la obligación para la Administración de contabilizar la deuda correspondiente relativa al contrato en ejecución. Ahora bien, ello no significa que automáticamente y en cualesquiera circunstancias se produzca dicha consecuencia. Como se ha visto, para evitarlo, junto con la necesidad de que el concesionario asuma "la mayor parte del riesgo de construcción", es preciso además que dicho concesionario asuma también el riesgo de disponibilidad o el riesgo de demanda. Basta con que concurra cualquiera de estos dos últimos (junto con la asunción de la mayor parte del riesgo de construcción) para evitar que los activos resultantes de una acción pública-privada deban ser registrados contablemente en el balance de los gobiernos.

En definitiva, asegurar una demanda mínima al concesionario constituye un riesgo cierto de tener que contabilizar la operación por parte de la Administración. La obligación o no de hacerlo así dependerá, a mi juicio, de la horquilla de demanda no garantizada por la Administración (recorrido en el que operará con plenitud el principio de riesgo y ventura), y fundamentalmente del hecho de que efectivamente se asuma por el concesionario el riesgo de disponibilidad, estableciéndose en el Pliego mecanismos correctores que reduzcan de manera significativa los pagos periódicos al concesionario como consecuencia de la reducción en la entrega por el socio privado del volumen contractualmente acordado o cuando no se cumplen los estándares de calidad establecidos.

\section{- Retribución del concesionario.}

La LCSP, como ya hiciera el TRLCAP, establece un sistema flexible de retribución al concesionario, lo que permite distintas soluciones posibles para amoldarse a las circunstancias y necesidades de cada caso.

El artículo 7 de la LCSP señala que la contraprestación a favor del concesionario consiste "o bien únicamente en el derecho a explotar la obra, o bien en dicho derecho acompañado del de percibir un precio" (no se alude en este precepto a "cualquier otra modalidad establecida en este titulo" que se contenía en el precepto equivalente del TRLCAP, esto es, el artículo 220.1). Por su parte, el artículo 238 de la LCSP dispone que el concesionario "tendrá 
derecho a percibir de los usuarios o de la Administración una retribución por la utilización de la obra en la zona prevista en el pliego de cláusulas administrativas particulares y de conformidad con lo establecido en este artículo".

De ello se desprende que en todo caso el concesionario debe explotar la obra, aunque, como se ha señalado, no necesariamente debe tratarse de una explotación omnicomprensiva física o funcionalmente. El concesionario percibirá la retribución correspondiente derivada de dicha explotación, que podrá ser abonada por los usuarios mediante el pago de las tarifas correspondientes, por la Administración o a través de un sistema mixto (parte los usuarios y parte la Administración).

Con independencia de ello (retribución derivada de la explotación de la obra), además es admisible que la Administración pueda abonar "un precio" al concesionario, sin que asuma en este caso la condición de retribución por la explotación de la obra. No es extraño en la práctica que la Administración reconozca al concesionario el derecho a explotar la obra junto con el derecho a percibir de la propia Administración y a fondo perdido una cantidad de dinero. Esta es una de las vías posibles para hacer rentable la ejecución de un contrato que, en otro caso y atendiendo a los términos en los que se haya configurado (plazo, importe de las tarifas a cobrar a los usuarios, etc.), podría no ser viable desde un punto de vista económico.

Como se ve, el sistema admite distintas modalidades, incluido el denominado "peaje en sombra". En este caso, se sustituirá el abono por los usuarios de la tarifa correspondiente, por el pago al concesionario directamente por la Administración del importe resultante de determinados parámetros previstos en el Pliego: número de usuarios, importe por usuario, coeficientes correctores en función de la calidad del servicio, etc.

Las tarifas a abonar por los usuarios serán fijadas por el órgano de contratación en el acuerdo de adjudicación, operando, según dispone el artículo 238.2 de la LCSP, como tarifas máximas, pudiendo el concesionario aplicar tarifas inferiores cuando lo estimen conveniente.

Ahora bien, esta posibilidad que ofrece el citado precepto legal no podría amparar, a mi juicio, situaciones discriminatorias. Nada impediría, por tanto, que el concesionario pudiera establecer tarifas reducidas para determinados colectivos, si bien deberá aplicar dichas tarifas reducidas a todos aquellos usuarios que formen parte del colectivo respectivo. No hay que perder de vista que quien explota la obra pública no deja de ser un concesionario de la Administración que presta, en definitiva, un servicio público (si se quiere en sentido amplio), y al que por tal razón le serán especialmente exigibles principios como el citado de no discriminación.

Es admisible que el Pliego correspondiente pueda establecer mecanismos correctores en función de los rendimientos de la demanda de utiliza- 
ción de la obra y, en su caso, de los beneficios derivados de la explotación de la zona comercial. Ya me he referido a ello al tratar la cuestión fundamentalmente desde la perspectiva del impacto que tal situación puede generar atendiendo a las normas de contabilidad Eurostat. En todo caso, debe destacarse la admisibilidad desde un punto de vista jurídico de que pueda configurarse un contrato en el que la Administración asegure el canon de demanda en los términos que estime oportunos.

Ahora bien, a mi juicio existe un límite natural derivado del propio principio de riesgo y ventura que rige tanto en la fase de construcción como de explotación, y es que no parecería admisible que durante la fase de explotación se asegurara completamente al concesionario el canon de demanda ofertado, pues ello equivaldría a dejar prácticamente sin efecto el aludido principio de riesgo y ventura. Dicho esto, sin embargo, la LCSP no establece límites máximos o mínimos, de manera que la horquilla de oscilación del canon de demanda sin que opere el reequilibrio a favor o en contra del concesionario, es ciertamente amplio, pues la Ley se limita a remitirse a lo que se establezca en el Pliego correspondiente.

Finalmente, podrá preverse en el Pliego que el concesionario explote, directa o indirectamente, zonas comerciales vinculadas a la concesión. La utilidad de este instrumento como mecanismo de retribución del concesionario está fuera de toda duda, puesto que permitirá que las tarifas que oferte sean inferiores, con la reducción de coste que ello supondrá para los usuarios y para la Administración.

En todo caso, como ya se ha destacado, lo que a mi juicio no admite la Ley es que el contrato de concesión de obras públicas se configure sobre la base de que el concesionario sólo vaya a explotar la zona complementaria de carácter comercial. Cuando el artículo 231 de la LCSP se refiere a que estas zonas o espacios deben ser explotados conjuntamente con la obra por el concesionario, está exigiendo que haya una efectiva explotación de la obra, aunque - se insiste - pueda no ser omnicomprensiva. Cuestión distinta es que pudiera darse una situación tal que la explotación de tales zonas comerciales implicara unos ingresos suficientes como para que la explotación de la obra pública pudiera realizarse sin pago alguno por los usuarios o por la Administración. Lo que la Ley exige es que el concesionario explote la obra pública, pero no prohíbe que pueda no llegar a abonársele importe alguno directamente imputable a dicha explotación, si la retribución que percibe el concesionario vía explotación de la zona comercial es suficiente para hacer viable y atractiva económicamente la ejecución del contrato. 
La modificación del contrato de concesión de obras públicas se regula en los artículos 226 y 233 de la LCSP, así como también en el artículo 202 del mismo texto legal, referido este último a la regulación de la modificación de los contratos administrativos en general.

El artículo 226 regula la modificación del "proyecto" y se inserta en la Sección correspondiente a la "Construcción de las obras objeto de concesión". Hay que interpretar, por tanto, que el citado precepto se está refiriendo a la modificación del proyecto durante la fase de ejecución de las obras. De hecho, el artículo 226.2 reconoce al concesionario la posibilidad de solicitar la resolución del contrato cuando el órgano de contratación imponga modificaciones "en la fase de ejecución que incrementen o disminuyan la obra en un porcentaje superior al 20 por ciento del importe total de las obras inicialmente previstas o representen una alteración sustancial del proyecto inicial'.

Ahora bien, convine aclarar dos expresiones que no siempre se distinguen adecuadamente, tampoco en la LCSP. Me refiero a la "modificación del proyecto" y a la "modificación del contrato". De hecho el artículo 226.1 señala que podrán introducirse "modificaciones en el proyecto" en los casos previstos y en la forma establecida en el artículo 202, precepto que se titula "modificaciones de los contratos" (no de los "proyectos").

En realidad, la modificación del proyecto de obras llevará consigo la correspondiente modificación del contrato del que forma parte. Sin embargo, la modificación del contrato puede producirse al margen de una modificación del proyecto de obras. Por ejemplo, una alteración en el plazo de duración del contrato constituye una modificación del contrato que, sin embargo, no tiene que afectar necesariamente al proyecto de obras.

Partiendo de esta consideración, el artículo 226 de la LCSP, como se dice, se está refiriendo específicamente a la modificación del proyecto de obras cuando todavía se encuentra en ejecución. Podrá modificarse dicho proyecto (y como consecuencia de ello, el contrato) en los casos previstos en el artículo 202, en cuanto reconoce la prerrogativa de la Administración para introducir modificaciones en el contrato ya perfeccionado siempre que se justifique en razones de interés público y tenga como finalizad atender a causas imprevistas, sin que estas modificaciones puedan afectar a las condiciones esenciales del contrato.

No voy a profundizar en el alcance de la prerrogativa de modificación si bien únicamente quiero destacar ahora que, como se observa, el artículo 202 de la LCSP permite su utilización para atender a "causas imprevistas", es decir, ha desaparecido la expresión "necesidades nuevas" que también se recogía en el artículo 101.1 del TRLCAP. No obstante, a pesar de que el objetivo sin duda ha sido restringir la utilización de los modificados, sin embargo la expresión "causas imprevistas" es lo suficientemente amplia y 
genérica como para gozar de un efecto potencialmente similar al que se desprendía de la utilización de ambas expresiones ("circunstancias nuevas" o "causas imprevistas") en el TRLCAP.

Por su parte, el artículo 233 de la LCSP se titula "Modificación de la obra pública”, precepto que tiene un objetivo similar al artículo 226, si bien en este caso no por referencia exclusiva a la modificación del proyecto de obras en fase de ejecución del mismo (antes del comienzo de la fase de explotación de la obra pública). Aunque sin duda era innecesario regular en dos preceptos distintos la modificación en el marco del contrato de concesión de obras públicas, lo cierto es que el artículo 233, en mi opinión, es omnicomprensivo, de manera que cubriría al menos la regulación aplicable a las modificaciones que no tengan cabida en el artículo 226 de la LCSP.

Así, el artículo 233 permite — también por remisión al artículo 202introducir modificaciones en el contrato de concesión de obras públicas, lo que puede materializarse (i) modificando o ampliando de la obra pública o (ii) modificando el contrato sin necesidad de alterar la obra pública, sino sólo alguno o algunos de los términos en los que se explota. Por ejemplo, el artículo 241.2. ${ }^{\text {) }}$ de la LCSP dispone que la Administración restablecerá el equilibrio del contrato cuando la Administración modifique, por razones de interés público, las condiciones de explotación de la obra.

Cuando la modificación afecta al equilibrio económico de la concesión, procederá la aplicación de los instrumentos dirigidos al mantenimiento del equilibrio económico del contrato, en los términos señalados en el artículo 241 de la LCSP. A mi juicio, el artículo 241.3 no establece un orden de prelación en relación los instrumentos de reequilibrio en el mismo enumerados. Ello no obsta para que los Pliegos puedan establecer dicho orden de prelación, lo que sin duda se traduciría en una autolimitación por parte de la Administración.

En cuanto a la posibilidad de resolver el contrato como consecuencia de las modificaciones introducidas, en el ámbito del contrato de concesión de obras públicas únicamente se reconoce tal posibilidad al concesionario cuando se introduzcan modificaciones en la fase de ejecución que incrementen o disminuyan la obra en un porcentaje superior al 20 por ciento del importe total de las obras inicialmente previsto o representen una alteración sustancial del proyecto inicial (artículo 226.2 de la LCSP). Ello no obsta para que en el Pliego correspondiente puedan establecerse las causas específicas de resolución del contrato, pues, en definitiva, el artículo 245.k) de la LCSP permite que en otras leyes o en el contrato correspondiente puedan establecerse otras causas de resolución del contrato de concesión de obras públicas distintas de las enumeradas en el artículo 245 de la LCSP. 


\section{FINANCIACIÓN}

La disposición derogatoria de la LCSP mantiene en vigor el Capítulo IV del Título V del Libro II, comprensivo de los artículos 253 a 260, ambos inclusive, del TRLCAP. Por su parte, la disposición final décima de la LCSP señala que en el plazo de un año a partir de la entrada en vigor de esta Ley, el Gobierno someterá al Congreso de los Diputados un proyecto de Ley en el que regulen las modalidades de captación de financiación en los mercados por los concesionarios de obras públicas o por los titulares de contratos de colaboración entre el sector público y el sector privado, así como el régimen de garantías que puede aplicarse a dicha financiación.

Los citados artículos 253 a 260 del TRLCAP (junto con otros preceptos concordantes) sin duda introdujeron certidumbre jurídica respecto al régimen aplicable en cuanto a la los requisitos de financiación y sus garantías. Como ya se ha destacado, el importante esfuerzo de financiación por parte del concesionario que normalmente lleva aparejado este tipo de contratos, exigía ofrecer a las entidades financiadoras un marco legal lo más claro posible, articulando los mecanismos que permitieran la obtención de financiación privada, se articule o no en cada caso como un verdadero "project finan$c e$ ". Con independencia de las modulaciones que puedan establecerse en cada Pliego, lo cierto es que la citada regulación vino a colmar un vacio hasta entonces existente.

Una de las notas características del régimen general en materia de financiación privada en el marco del contrato de concesión de obras públicas es la denominada "diversificación de las fuentes de financiación", que procura la introducción de un régimen financiero específico del contrato que beneficia al concesionario y facilita en última instancia los mecanismos de financiación de la concesión, haciéndola más atractiva para el capital privado (obtención de préstamos y créditos con entidades de crédito; emisión de obligaciones por la sociedad concesionaria; incorporación a títulos negociables de los derechos de crédito de concesionario; créditos participativos). Y junto a ello, se ofrecen instrumentos de garantía en relación con dicha financiación, que incluyen la hipoteca de la concesión y la pignoración de las acciones representativas del capital social de la sociedad concesionaria. Ello con independencia, además, de la posibilidad de pignorar los derechos que el concesionario tenga frente a la Administración o frente a terceros (por ejemplo, Compañías aseguradoras, empresa que construye las obras), y del contrato de apoyo de los accionistas de la sociedad concesionaria en los términos que se haya pactado con la entidad financiadora. 
Conforme al artículo 236 de la LCSP, las obras públicas objeto de concesión serán financiadas, total o parcialmente, por el concesionario que, en todo caso, asumirá el riesgo en función de la inversión realizada. No obstante, cuando existan razones de rentabilidad económica o social, o concurran singulares exigencias derivadas del fin público o interés general de la obra objeto de concesión, la Administración concedente podrá participar en la financiación mediante (i) subvenciones (cantidades a fondo perdido) y (ii) préstamos reintegrables, con o sin intereses. Además, es posible la articulación de mecanismos de cofinanciación junto con otras Administraciones u organismos nacionales o internacionales, de acuerdo con los convenios suscritos al efecto.

El concesionario puede acudir al crédito privado para financiarse, lo que sin embargo no está exento de controles por parte de la Administración, tanto en lo que se refiere a su obtención como a las garantías que eventualmente se presten. En este sentido convendría distinguir los requisitos para obtener financiación ajena y las garantías que pueden otorgarse a tal fin.

\section{ObTENCión DE FinANCIACión AJENA}

En cuanto a la obtención de financiación por parte del concesionario, en los Pliegos suele exigirse que los licitadores, con un mayor o menor detalle, expongan cómo tienen proyectado financiarse. Es más, en muchas ocasiones la consistencia de las fuentes de financiación y el grado de vinculación por parte de las potenciales entidades financiadoras en fase de oferta, son objeto de la correspondiente puntuación. También se puntúa a veces el mayor porcentaje — que sobrepase el mínimo exigido— de aportación de fondos propios a la sociedad concesionaria por parte de los licitadores (accionistas de la sociedad concesionaria constituida a tal fin).

En todo caso, debe tenerse presente que no existe en la LCSP un precepto equivalente al artículo 224 del TRLCAP. En éste se sometía a comunicación al órgano de contratación -en el plazo de un mes desde su suscripción- la contratación por el concesionario de préstamos o créditos con entidades de crédito; cualquier otro medio de financiación privada se sometía a la previa autorización del órgano de contratación. No existe, como se dice, un precepto equivalente, de manera que sin perjuicio de lo que finalmente establezca al respecto la Ley que se anuncia sobre esta materia en la disposición final décima de la LCSP, habrá de estarse a lo que establezcan los Pliegos, ello sin perjuicio de la necesidad de obtener las autorizaciones pertinentes para la constitución de garantías, en los términos que a continuación se señalan. 


\section{GARANTÍAs A OTORGAR POR EL CONCESIONARIO}

Por lo que se refiere a las garantías que pueda otorgar el concesionario en el marco de la financiación ajena obtenida, la LCSP, como ya se ha destacado, mantiene en vigor los artículos 253 a 260 del TRLCAP. La hipoteca de la concesión (o la promesa de hipoteca) y la pignoración de las acciones de la sociedad concesionaria constituyen las garantías principales en este ámbito, aunque no las únicas.

En cuanto a la hipoteca, en la práctica, por una razón de ahorro de costes (fiscales, notariales), en muchas ocasiones lo que se otorga es una promesa de hipoteca, con el fin de que la entidad financiadora pueda en cualquier momento imponer o acordar su constitución. Ahora bien, como la entidad financiadora lo impondrá en situaciones de riesgo cierto o incumplimiento del concesionario, normalmente junto a la citada promesa de hipoteca se otorga por el concesionario un poder irrevocable a favor de la entidad financiadora, con el fin de que ésta pueda constituir la hipoteca sin la participación del concesionario. Incluso a veces, para cerrar el círculo, se obtiene desde un principio la autorización de la Administración para constituir la hipoteca, autorización que no suele estar sometida a plazo y que, por tanto, permite a la entidad financiadora constituir la hipoteca en cualquier momento posterior. La promesa de hipoteca junto con el poder irrevocable y la autorización ab initio de la Administración, ofrece un marco confortable para la entidad financiadora, lo que permitirá con mayor tranquilidad no exigir desde un principio la constitución de la hipoteca y, por tanto, evitará aumentar los costes del proyecto.

Por lo que se refiere a la pignoración de las acciones de la sociedad concesionaria, no existe una regulación específica en la LCSP sobre esta cuestión, lo que suele generar la duda de si hace falta obtener la previa autorización de la Administración para pignorar las acciones.

Si el Pliego prevé algo al respecto, habrá de estarse a lo en el mismo regulado. Pero lo cierto es que en muchas ocasiones nada se dice en los Pliegos, o a lo sumo se dispone que la ejecución de la prenda sobre las acciones de la sociedad concesionaria no constituye un supuesto en el que deban cumplirse los requisitos previsto en la Ley para la cesión de los contratos.

Pues bien, cuando no exista regulación sobre el particular, a mi juicio la diligencia mínima exigible debe llevar a comunicar a la Administración la pignoración que se pretende y a obtener de ella, si no la autorización previa (pues equivaldría a reconocer su exigencia), si al menos su no objeción o conformidad (que materialmente es muy parecido).

Debe tenerse presente que, en definitiva, la eventual ejecución de la prenda supondrá un cambio en el control de la sociedad concesionaria, lo 
que no es indiferente para la Administración, de manera que parece razonable que deba obtenerse previamente la conformidad de la Administración para constituir la prenda. Es más, incluso podría suscitarse si sería exigible también en estos casos la doble autorización como en las hipotecas (cuando se constituye y cuando se ejecuta), pues no es indiferente para la Administración quien finalmente controlará a la sociedad concesionaria.

Aparte de la hipoteca (o promesa de hipoteca) sobre la concesión y la prenda sobre las acciones representativas del capital social de la sociedad concesionaria, en la práctica, como garantía en el marco de la financiación ajena, se constituye prenda sobre los derechos que el concesionario tenga frente a la Administración, incluidas eventuales indemnizaciones a su favor en caso de extinción anticipada. En este aspecto, la determinación de la denominada "RPA" (responsabilidad de la Administración) suele ser el eje fundamental, para lo que habrá que examinar el Pliego concreto.

Es evidente que no es indiferente para la entidad financiadora el importe al que tendrá derecho el concesionario en el caso de extinción anticipada de la concesión. Dicho importe variará, y sustancialmente, según cual sea la causa que genere dicha extinción (imputable al concesionario, por culpa de la Administración, rescate, fuerza mayor). Obviamente, la entidad financiadora, a efectos del repago de la deuda, deberá ponerse en el peor escenario, esto es, resolución de la concesión por causa imputable al concesionario.

Por otro lado, debe tenerse presente que la expresión "RPA", muy acuñada en la práctica en este ámbito, sin embargo se utiliza en muchas ocasiones de manera confusa, pues a veces se considera que incluye sólo los importes a abonar al concesionario por la Administración por obra no amortizada en la fecha en la que se acuerda la resolución del contrato.

Desde la perspectiva de la financiación, lo determinante es conocer, hasta donde sea posible, las cantidades a las que tendría derecho el concesionario (por cualquier concepto) en caso de extinción anticipada del contrato, con el fin de valorar la viabilidad del efectivo repago de la deuda. En este contexto, la "RPA" incluiría no sólo lo que propiamente constituirían indemnizaciones a abonar por la Administración, sino también contraprestaciones por actividades realizadas por el concesionario (fundamentalmente, aunque no solo, obra pendiente de amortizar).

Así, el artículo 247.1 de la LCSP dispone que en los supuestos de resolución (no distingue), "la Administración abonará al concesionario el importe de las inversiones realizadas por razón de la expropiación de terrenos, ejecución de obras de construcción y adquisición de bienes que sean necesarios para la explotación de la obra objeto de la concesión. Al efecto, se tendrá en cuenta su grado de amortización en función del tiempo que restara para el término de la concesión y lo establecido en el plan económico-financiero". Obsérvese que en 
el artículo 247.1 de la LCSP se ha omitido la cita que se contenía en el precepto equivalente del TRLCAP (artículo 266.1), cuando señalaba que "si el concesionario hubiese contado entre sus recursos con financiación de terceros, sólo se le abonará el sobrante después de solventar las obligaciones contraidas con aquéllos". Nuevamente habrá que esperar a lo que establezca la Ley anunciada en la disposición adicional décima de la LCSP, si bien entretanto ha desaparecido, como se ve, la transcrita previsión establecida a favor de los financiadores.

En todo caso, los conceptos a que se refiere el artículo 247.1 de la LCSP con rigor no constituyen indemnizaciones, sino que responden al concepto de contraprestación. Aparte de ello, el concesionario o la Administración tendrán, en su caso, derecho a ser indemnizados en los casos y con el alcance señalado en el artículo 247 de la LCSP.

La entidad financiadora valorará la "RPA" (incluyendo indemnizaciones propiamente dichas y contraprestaciones) en cada uno de los escenarios posibles (incumplimiento del concesionario, de la Administración o extinción sin que haya incumplimiento de ninguna de las dos partes), y normalmente, en trance de negociar el contrato de apoyo de los accionistas, se colocará en el peor escenario, esto es, la resolución de la concesión por incumplimiento del concesionario. En este caso, el concesionario tendrá derecho a percibir el importe correspondiente por los conceptos señalados en el artículo 247.1, importe que, sin embargo, podrá verse minorado por los daños y perjuicios que deba abonar a la Administración en lo que excedan de la garantía definitiva que se le incauta.

\section{EXTINCIÓN DEL CONTRATO DE CONCESIÓN DE OBRAS PÚBLICAS}

La extinción puede producirse, como en todos los contratos, de tres maneras: (i) por cumplimiento, (ii) por invalidez y (iii) por resolución. A continuación se exponen los aspectos más relevantes sobre cada una de ellas.

\section{EXTINCIÓN POR CUMPLIMIENTO}

El contrato de concesión de obras públicas es único, de manera que las tres fases en las que puede descomponerse (redacción de proyecto, ejecución de obras y explotación) forman parte de un solo contrato. Únicamente podrá considerarse cumplido una vez que haya concluido la última de las citadas fases, es decir, la fase de explotación. Transcurrido el plazo de vigencia 
de la concesión, procederá la reversión a favor de la Administración de la obra pública, las zonas complementarias anexas y los bienes e instalaciones incluidos en las zonas de explotación comercial. Quedarán igualmente extinguidos todos los contratos vinculados a la concesión y a la explotación de sus zonas comerciales y procederá la devolución de la garantía definitiva constituida por el concesionario.

\section{EXTINCIÓN POR INVALIDEZ DEL CONTRATO}

Habrá de estarse a lo dispuesto en los arts. 31 a 36 de la LCSP, que responden al mismo esquema trazado por los artículos 61 y ss. del TRLCAP, razón por la que no nos detenemos en ello. Únicamente destaco los siguientes aspectos:

- La declaración de nulidad de los actos preparatorios del contrato o del acto administrativo de adjudicación provisional o definitiva, cuando sea firme, llevará consigo en todo caso la del contrato mismo, que entrará en fase de liquidación (artículo 35.1 de la LCSP).

Debe observarse que ahora se añade la referencia a la adjudicación provisional, figura que revive en la LCSP. Además, hay que tener en cuenta que la adjudicación provisional, aunque jurídicamente constituye un acto de trámite (se inserta en el seno del procedimiento inacabado), sin embargo se asimila en cierta medida a los actos finales, como lo demuestra el hecho de que la LCSP ha configurado un recurso administrativo especial que podrá interponerse contra la adjudicación provisional, y cuya resolución abrirá las puertas al contencioso-administrativo.

Sin duda, el recurso especial en materia de contratación (previsto sólo para algunos contratos y que puede ser utilizado en relación con los actos administrativos que se citan en el artículo 37.2 de la LCSP), constituye un importante avance en la articulación de un sistema que permita corregir irregularidades detectadas en el seno del procedimiento de adjudicación. Su eficacia se encuentra ligada al hecho de que, en particular, cuando se impugna el acto de adjudicación provisional, tendrá el efecto automático de suspender la tramitación del procedimiento hasta que se resuelva expresamente dicho recurso por el órgano de contratación.

Lo que no aclara el artículo 37 de la LCSP es si se produce alguna merma en la posibilidad de impugnación de la adjudicación definitiva en el caso de que previamente no se hubiera recurrido el acto de adjudicación provisional. A mi juicio, la posibilidad de impugnar la adjudicación definitiva no puede quedar mediatizada por el hecho de no haberse utilizado el recurso especial 
contra la adjudicación provisional, puesto que ésta es sólo una posibilidad y no una obligación. Cuando el artículo 37.1 alude a que "deberâ" interponerse el recurso especial antes de acudir a la jurisdicción contencioso-administrativa, en realidad lo que se está queriendo decir es que cuando se decida impugnar la adjudicación provisional, habrá que agotar la vía administrativa (recurso especial) antes de acudir ante la jurisdicción contencioso-administrativa; pero no que haya de recurrirse necesariamente la adjudicación provisional para estar legitimado para impugnar la definitiva. Esta interpretación encuentra apoyo en el propio derecho fundamental a la tutela judicial efectiva.

En todo caso, si finalmente se recurre la adjudicación provisional ante la jurisdicción contencioso-administrativa y no se recurre, en cambio, la adjudicación definitiva, se correría el riesgo de que pudiera considerarse la adjudicación definitiva como un "acto consentido". Para evitar este riesgo, lo aconsejable es que se recurra también el acto de adjudicación definitiva, sin perjuicio de pedir, en su caso, la acumulación en sede jurisdiccional. Pero situándonos en la hipótesis de que no se hubiera recurrido la adjudicación definitiva, en mi opinión el artículo 35.1 de la LCSP permite concluir que la declaración de nulidad de la adjudicación provisional (con independencia de que se haya impugnado o no la adjudicación definitiva) haría decaer el contrato mismo.

- No obstante lo anterior, si la declaración administrativa de nulidad de un contrato produjese un grave trastorno al servicio público, podrá disponerse en el mismo acuerdo la continuación de los efectos de aquél y bajo sus mismas cláusulas hasta que se adopten las medidas urgentes para evitar el perjuicio (artículo 35.3 de la LCSP).

Constituye ésta una demostración más de la imposibilidad de aplicar con rigidez la teoría de las nulidades. Obsérvese que estamos ante la declaración de nulidad de un contrato (o del acto o actos que le sirven de soporte). A pesar de que con rigor el efecto de dicha declaración de nulidad consiste en que jurídicamente deja de existir el contrato (no entro en la discusión relativa al efecto retroactivo), lo cierto es que se impone la realidad frente a la aplicación rigurosa de determinadas categorías jurídicas. Y así, un contrato que jurídicamente no existe, sin embargo sigue desplegando sus efectos en lo indispensable para evitar el grave trastorno al servicio público que en otro caso se produciría.

- Finalmente, la declaración de invalidez de un contrato (o la de los actos preparatorios del mismo o el de adjudicación) implicará que las partes deban restituirse recíprocamente las cosas que hubiesen recibido en virtud del mismo, y si esto no fuera posible se devolverá su valor. Además, la parte que resulte culpable deberá indemnizar a la otra por los daños y perjuicios que haya sufrido. 
Debe tenerse presente en este sentido que la Administración responde por los dańos y perjuicios que hubieran podido ocasionarse como consecuencia de la anulación de sus actos administrativos. Seńala el artículo 142.4 de la Ley 30/1992 que la anulación en vía administrativa o por el orden jurisdiccional contencioso-administrativo de los actos o disposiciones administrativas no presupone derecho a la indemnización, pero si la resolución de la disposición impugnada lo fuese por razón de su fondo o forma, el derecho a reclamar prescribirá al año de haberse dictado la sentencia definitiva, no siendo de aplicación lo dispuesto en el apartado 5 de ese mismo precepto.

Esta previsión legal ha sido interpretada en numerosas ocasiones por el Consejo de Estado en el sentido de que el artículo 142.4 ni excluye ni anuda automáticamente la responsabilidad patrimonial de la Administración a la declaración de invalidez de un acto administrativo. Habrá que analizar caso por caso, examinando si concurren los requisitos exigidos en los artículos 139 y siguientes de la Ley 30/1992 para que proceda declarar dicha responsabilidad (plazo, relación de causalidad, imputación, lesión indemnizable). En todo caso, normalmente la causante de la declaración de invalidez del acto preparatorio, de la adjudicación provisional, de la definitiva o del contrato mismo será la Administración, a la que por tal motivo le sería imputable el perjuicio producido.

\section{Resolución DEL CONTRATO}

Ya se ha destacado alguna novedad de la LCSP en esta materia, como por ejemplo la desaparición en el artículo 247.1 de la LCSP de la referencia que se contenía en el precepto equivalente del TRLCAP (artículo 266.1) a que, en caso de resolución por cualquier motivo, "si el concesionario hubiese contado entre sus recursos con financiación de terceros, sólo se le abonará el sobrante después de solventar las obligaciones contraidas por aquéllos".

Junto a las causas de resolución del contrato que con carácter general se recogen en el artículo 206 de la LCSP (y que resultan de aplicación a todos los contratos, incluido el de concesión de obras públicas, según de desprende del artículo 245.k de la LCSP), el artículo 245 enumera las causas específicas de resolución del contrato de concesión de obras públicas, y lo hace en similares términos al artículo 264 del TRLCAP, razón por la que no me detengo en ello. Únicamente me refiero brevemente a algunas cuestiones relacionadas con esta materia:

- Cualquiera que sea la causa de resolución del contrato, el concesionario tiene derecho a percibir el importe de las inversiones realizadas 
por razón de la expropiación de los terrenos, ejecución de obras de construcción y la adquisición de bienes que sean necesarios para la explotación de la concesión, debiendo tenerse en cuenta a tal efecto su grado de amortización. Como ya he destacado, el abono al concesionario por estos conceptos carecerá propiamente de naturaleza indemnizatoria, y responderá más bien al concepto de contraprestación. En definitiva, se está retribuyendo al concesionario lo que ha construido, que queda a favor de la Administración.

- Cuando el contrato se resuelva por incumplimiento culpable del concesionario, le será incautada la garantía definitiva constituida y, además, deberá indemnizar a la Administración los daños y perjuicios ocasionados en lo que exceda del importe de la garantía incautada (artículo 247.4 de la LCSP).

Aunque esta consecuencia ya estaba prevista en el TRLCAP, hay que destacar la importancia de que se mantenga esta previsión específica para el contrato de concesión de obras pública, especialmente si se tiene en cuenta que el artículo 208 de la LCSP no prevé, con carácter general, la incautación de la garantía definitiva en caso de resolución por incumplimiento del contratista (o al menos no lo establece claramente). Dispone el apartado 4 del citado precepto legal que "cuando el contrato se resuelva por incumplimiento culpable del contratista, éste deberá indemnizar a la Administración los daños y perjuicios ocasionados. La indemnización se hará efectiva, en primer término, sobre la garantía que, en su caso, se hubiese constituido, sin perjuicio de la subsistencia de la responsabilidad del contratista en lo que se refiere al importe que exceda del de la garantía incautada". Y añade su apartado 5 que "en todo caso el acuerdo de resolución contendrá pronunciamiento expreso acerca de la procedencia o no de la pérdida, devolución o cancelación de la garantía que, en su caso, hubiese sido constituida".

Es posible que al resolverse el contrato de concesión de obras públicas por causa imputable al concesionario, concurra alguna de las tres situaciones siguientes: (i) que el importe de los dańos y perjuicios causados sea inferior al importe de la garantía incautada, supuesto en el que procederá la incautación de la garantía completa, si bien el concesionario no deberá abonar importe adicional alguno a la Administración en concepto de daños y perjuicios; (ii) que coincidan el importe de la garantía incautada y el de los daños y perjuicios causados, en cuyo caso procederá exclusivamente la incautación de la garantía; y (iii) que la cuantía de los daños y perjuicios causados sea superior a la garantía, procediendo entonces la incautación de la garantía completa y el abono de la diferencia entre el importe de ésta y la cuantía de los dańos y perjuicios efectivamente causados por el incumplimiento del concesionario. 
- Si la resolución del contrato se produjera por causa imputable a la Administración, ésta deberá indemnizar al concesionario por los daños y perjuicios que se le hubieran causado. Similares efectos se producen cuando la Administración, sin incumplir sus obligaciones, acuerda el rescate, la supresión de la explotación de la obra pública por razón de interés público o se produce la imposibilidad de dicha explotación de la obra. Para determinar la cuantía de la indemnización se tendrán en cuenta los beneficios futuros que el concesionario dejará de percibir, atendiendo a los resultados de explotación en el último quinquenio cuando resulte posible, y a la pérdida del valor de las obras e instalaciones que no hayan de ser entregadas a la Administración, considerando su grado de amortización.

- Aparte de los casos de fuerza mayor, es posible también que se resuelva el contrato por causa que no sea imputable ni a la Administración ni al concesionario. Así podrá ocurrir, por ejemplo, en supuestos de extinción de la persona jurídica de la sociedad concesionaria, declaración concursal o resolución por mutuo acuerdo. En estos casos, en los que la resolución no sea imputable a ninguna de las partes, procederá la devolución de la garantía definitiva al concesionario y el abono de la inversión realizada (no amortizada), si bien en principio ninguna de las partes en el contrato deberá abonar a la otra los eventuales daños y perjuicios que la resolución anticipada hubiera podido producir, sin perjuicio de lo que pudieran acordar las partes en el supuesto de resolución por mutuo acuerdo. 
